\title{
Pricing Decisions in a Competitive Closed-Loop Supply Chain with Duopolistic Recyclers
}

\author{
Doo Ho Lee 1 iD \\ Division of Software, Media, and Industrial Engineering, Kangwon National University, 346 Joongang-ro, Samcheok-si, \\ Gangwon-do 29513, Republic of Korea \\ Correspondence should be addressed to Doo Ho Lee; enjdhlee@gmail.com
}

Received 5 February 2020; Accepted 7 March 2020; Published 18 April 2020

Guest Editor: Shib Sankar Sana

Copyright $(2020$ Doo Ho Lee. This is an open access article distributed under the Creative Commons Attribution License, which permits unrestricted use, distribution, and reproduction in any medium, provided the original work is properly cited.

In this study, we consider a three-echelon closed-loop supply chain consisting of a manufacturer, a collector, and two duopolistic recyclers. In the supply chain, the collector collects end-of-life products from consumers in the market. Then, both recyclers purchase the recyclable waste from the collector, and each recycler turns them into new materials. The manufacturer has no recycling facilities; therefore, the manufacturer only purchases the recycled and new materials for its production from the two recyclers. Under this scenario, price competition between recyclers is inevitable. With two pricing structures (Nash and Stackelberg) of the leaders group and three competition behaviors (Collusion, Cournot, and Stackelberg) of the followers group, we suggest six different pricing game models. In each of them, we establish a pricing game model among the members, prove the uniqueness of the equilibrium prices of the supply chain members, and discuss the effects of competition on the overall supply chain's profitability. Our numerical experiment indicates that as the price competition between recyclers intensifies, the supply chain profitability decreases. Moreover, the greater the recyclability degree of the waste is, the higher the profits in the supply chain become.

\section{Introduction}

Over the past few decades, profitability improvements and cost leadership have been the main goals of supply chain management. However, more recently, the increasing rates of environmental degradation and resource depletion triggered by rapid industrialization have shifted this focus to socioenvironmental issues; in the context of supply chain research, this has led to more concern about sustainability, with the concept of supply chain sustainability emerging [1]. For many industries, supply chain sustainability is one of the most critical tasks of their operations and long-term planning. In addition to business performance of the supply chain, environmental and social effects of the supply chain have been increasingly perceived as critical aspects of supply chain performance by shareholders. As a result, sustainable supply chain management has become one of the main interests of business managers and stakeholders [2-4].
The supply chain is an important branch of operational management, and it has a significant impact on the environment through hazardous gas emission and pollution. Companies in various industries are now attempting to minimize their environmental impacts by integrating environmental issues into their supply chain operations. The integration of environmental issues into supply chain management practices is referred to as green supply chain management [5-8]. Green supply chain has become an important research topic in academia and industry. This topic includes environmental management such as ecofriendly product/service designs, green purchasing, reuse, remanufacturing, and recycling [9-11]. Among these solutions, recycling and reuse are considered more desirable because they require less of a quality-of-life compromise of the type closely linked to intensive material consumption [12]. Many countries have been promoting the policies related to the economic resource circulation. For example, Japan has been encouraging what is termed a sound 
material-cycle society by implementing the $3 \mathrm{R}$ (reduce, reuse, and recycle) strategy [13]. Material and energy flows must become part of an increasingly sustainable and circular economy, a concept introduced by the European Union as follows: In a circular economy, the value of products and materials is maintained for as long as possible. Waste and resource use are minimized, and when a product reaches the end of its life, it is used again to create further value. This can bring major economic benefits, contributing to innovation, growth, and job creation. In 2018, Apple announced that the 2018 models of its MacBook Air and Mac mini would both be manufactured with 100 percent recycled aluminum. Additionally, the Mac mini would be constructed from 60 percent recycled plastic.

Recycling is the process of collecting and processing waste that would otherwise be thrown away as trash and turning the waste into new products for environmental protection. It also includes the optimal management of waste disposal facilities. Another aim of recycling is to encourage ecofriendly management and to manage limited supplies of resources. The supply chain term refers to a type of systematic collaboration between people, processes, and information to create tangible or intangible value and deliver it to consumers. The main purpose of supply chain management is to facilitate better material and information flows among stakeholders in the supply chain. This creates a better relationship between stakeholders in the supply chain, which increases the profitability of the entire supply chain $[14,15]$. With the depletion of resources around the world, waste from end-of-life products is becoming an important resource that can be managed globally. As consumers' interest in environmental issues has increased along with the amounts of waste, industrialists and researchers are now focusing on sustainable products. Reverse and closed-loop supply chains are well adapted to sustainability goals [16]. Generally, a reverse supply chain and closed-loop supply chain consist of certain operations such as collecting recyclable waste, transforming it into new materials, and transferring these materials to a manufacturer for remanufacturing. A dual channel for collection can also be implemented in the supply chain. Sometimes, it is found that dual-channel recycling outperforms single-channel recycling $[17,18]$.

Recyclability is a characteristic of a material that can retain useful chemical and/or physical properties after achieving their original purpose, thus allowing it to be reused or remanufactured into additional products through a recognized process. Thus, recyclability must be observed and considered as the baseline during design, production, and waste management activities. With the development of information and communication technology (ICT), the demand for electronic products has increased greatly, and this has led to more generation of waste electrical and electronic equipment (WEEE). The disruption of rare-earth metal exports to Japan, triggered by the Senkaku Islands dispute in 2010, led to confusion not only in Japan but also in the global market, paradoxically emphasizing the importance of securing resources. In 2016, the potential recovery of seven precious resources, specifically iron, copper, gold, silver, aluminum, palladium, and plastics in WEEE, amounts to approximately 12.3 million tonnes in Europe [19]. In light of this fact, the recyclability of WEEE plays a key role not only in terms of environmental protection but also with regard to the stable supply and demand for various ICT products.

Based on these observations, this paper deals with a closed-loop supply chain in which two recyclers compete with each other. More specifically, each recycler purchases recyclable waste from a collector, recycles the waste, and finally sells the recycled materials to a manufacturer. In this process, the two recyclers compete with regard to the selling prices of their recycled materials. The aim of this study is to investigate pricing and ordering decisions during the waste recycling process in a three-echelon closed-loop supply chain with duopolistic recyclers using a game-theoretic framework. Due to the competition between recyclers, the price offered by one recycler affects not only the price of the other recycler but also those of all other members in the supply chain. Therefore, demand and profit in the supply chain are sensitive in all cases to price competition. This study proposes several pricing game models based on pricing structures and competitive behavior. The main research questions for this study are as follows:

(i) How can each member in the supply chain increase the profit?

(ii) What are the profits and equilibrium variables of the supply chain members?

(iii) How strong is the effect of the price competition between recyclers in the supply chain?

(iv) Does the recyclability degree of wastes have a positive effect on the profit of each member in the supply chain?

(v) Does an imbalance in the market share between competitors affect the profit of the entire supply chain?

In order to answer the above questions, we revisit Jafari et al.'s study [20] by considering price competition between recyclers. The main contributions of this research are threefold. First, the impact of price competition between recyclers with different competitive behaviors on the sustainability of the supply chain is investigated. Second, our study concerns the economic as well as environmental aspects of the supply chain. Third, we suggest six different pricing game models and show the existence of equilibrium solutions for each game. Finally, we compare the results of the six pricing game models through a numerical example.

The rest of this study is organized as follows. In Section 2, we present a brief overview of the relevant literature, after which we introduce the six pricing game models and then review the notations used and assumptions in Section 3. In Section 4, we conduct a preliminary analysis of our main results. Section 5 deals with the equilibrium quantities for each of the six pricing game models. Various numerical experiments are conducted in Section 6 to investigate the effects of certain parameters on the equilibrium quantities. In Section 6, we give a summary of the paper and provide future research topics. 


\section{Literature Review}

In this section, we review the relevant literature considering the main stream of research studies: recycling issues in the sustainable supply chains.

The economic and environmental benefits of sustainable supply chain management have been widely recognized over the past two decades, and the closed-loop supply chain (CLSC) has therefore attracted significant attention from both industry and academia. A CLSC consists of a forward and a reverse supply chain. The forward supply chain involves the movement of products from upstream suppliers to downstream consumers, while the reverse supply chain involves the movement of used or end-of-life products from consumers to upstream suppliers [21]. In a CLSC, it is suggested that once the products are sold to consumers, the responsibilities of producers for dealing with sustainability issues should not end. There should be some accountability with regard to the impacts of the products during their consumption and during the postconsumption phase. Accordingly, waste management programs should be adopted. As a result, the linear paradigm of the supply chain becomes circular. Input materials into the CLSC are reduced because some of the generated waste is retrieved to be reused as resources. Hence, the energy and resource dependencies are reduced without affecting economic growth [22]. The CLSC stimulates the circulation of resources by slowing, narrowing, intensifying, and closing resource loops [23]. From this point of view, recycling is one of the major avenues used to improve waste management systems [12]. Several studies have investigated this issue. Savaskan et al. [24] dealt with a CLSC capable of product collection and recycling and found that retailer collection is the most effective means of product collection activity for the manufacturer. Savaskan and Van Wassenhove [25] studied the reverse channel design and optimal pricing decisions of a CLSC in which two competing recyclers collect used products. Chen and Sheu [26] developed a differential game model established in view of sales competition and recycling dynamics as well as regulationrelated profit function. Atasu et al. [27] investigated the impact of collection cost structures on optimal reverse channel decisions based on the work of Savaskan et al. [24]. Hong et al. [28] investigated three reverse hybrid collection channel structures in a manufacturer-oriented CLSC and found that the retailer's and manufacturer's hybrid collection channel is the most effective. Huang et al. [18] studied the impacts of recycling competition on pricing and recycling strategies. They showed that dual-channel recycling outperforms a single-channel recycling. A similar problem with a different end-of-life product collection structure was studied by Wang et al. [29] and Modak et al. [30, 31]. Modak et al. proposed a two-echelon duopolistic retailer supply chain model with a recycling facility by considering the Cournot and Collusion behaviors of retailers. Saha et al. [32] considered pricing strategies in a dual-channel CLSC under three systems for the collection of used products: third-party collection, manufacturer collection, and retailer collection. Liu et al. [33] studied the dual-recycling channel collection to investigate pricing and best reverse-channel choice decisions. Their work suggested that the retailer dual-collecting model was the best channel structure for a CLSC. In a dual-reverse-supply chain, consumer preference was considered by Feng et al. [17], who assumed a case in which consumers return used products via three different recycling channels. Jafari et al. [20] considered a dual-channel recycling structure through a collector or a recycler. They considered recycling while assuming a smooth waste collection flow, i.e., with no shortcomings occurring on the collector's side. They established various Stackelberg game models to determine the equilibrium prices for recyclable waste, recycled materials, and finished products. By considering a more realistic situation of recycling, Giri and Dey [34] extended the model by Jafari et al. [20] to a CLSC with a secondary or backup supplier who supplies shortfalls of materials to tackle critical situations and obstacles preventing the smooth running of the supply chain. Wei et al. [35] studied a remanufacturing supply chain with dualcollecting channels under a dynamic setting and established three two-period game models by considering both the profit discount and competition between the two collecting channels. Jian et al. [36] explored collaborative collection effort strategies involving a third-party collector and an e-tailer based on the "internet + recycling" business model. Nielsen et al. [37] examined the effects of government subsidy policies in a CLSC and suggested that government organizations must inspect carefully the product types, power structures, and investment efficiency before implementing any subsidy policies. Saha et al. [38] also dealt with a CLSC under the influence of government incentives. They found that the greening level and used product return rate in a CLSC are always higher under retailer-led Stackelberg game.

More recently, many studies of corporate social responsibility (CSR) in a CLSC have been carried out due to growing consumer interest in environmental protection. Modak et al. [39] investigated a socially responsible supply chain with duopolistic retailers, using Cournot and Collusion games to demonstrate that a manufacturer's CSR has a significant effect on wholesale prices because intensive CSR practice can result in negative wholesale prices. Panda et al. [40] developed a socially responsible CLSC with recycling. They insisted that the channel's nonprofit maximizing motive through corporate social responsibility practices generated a higher profit margin than the profit maximizing objective and that there must be a recycling limit for the optimal benefit of the channel. Modak et al. [41] examined the influence of a manufacturer's social responsibility on the collection activity of a third party in a CLSC and showed that product recycling is directly affected by the manufacturer's corporate social responsibility concerns and that there must be a recycling threshold for the optimal benefit. Modak and Kelle [42] suggested social work donation (SWD) as a tool of CSR in a CLSC considering carbon taxes and demand uncertainty. They revealed that SWD is beneficial when used as an investment in CSR activity if the demand has a higher SWD elasticity parameter than the price sensitivity parameter. Dual-channel CLSC coordination under SWD was also analyzed by Modak et al. [43], who asserted that if a 
channel recycles used products and has socially concerned consumers, then consumers have the power to accelerate SWD and recycling simultaneously. An excellent survey on reverse logistics and CLSC management studies can be found in Kazemi et al. [44] and the references therein.

Although comprehensive research has been conducted on recycling and pricing issues in various sustainable supply chains, few studies have investigated price competition between recyclers in the recycling market. In this work, we consider forward and reverse supply chains where recyclable waste, recycled materials, and finished goods flow. From our pricing decision models, we investigate the effects of price competition between recyclers on the profits of the members in the supply chain and on the total profit of the supply chain. This work also discusses how an imbalance in the market share between recyclers affects the profit of the entire supply chain.

\section{Model Description and Assumptions}

3.1. Notations. To model the investigated supply chain, the following notations are used throughout the paper:

Index

$i$ : recyclers $(i=1,2)$

Decision variables

$P_{m}$ : selling price of the finished product offered by the manufacturer

$P_{r i}$ : selling price of the recycled material offered by the recycler $i$

$P_{c}$ : selling price of the recyclable wastes offered by the collector

\section{Parameters}

$C_{p}$ : unit production cost of the finished product to the manufacturer

$C_{r i}$ : unit recycling cost of the recyclable wastes to the recycler $i$

$C_{c}$ : unit collection cost of the end-of-life product to the collector

$\gamma$ : quantity of the recycled materials required to produce one unit of the finished product $(\gamma>1)$

$\theta$ : recyclability degree of the wastes $(0<\theta<1)$

$\alpha$ : potential market demand for the finished product $\beta_{m}$ : consumer's price sensitivity for the finished product

$\beta_{r}$ : manufacturer's price sensitivity for the recycled material

$\omega$ : cross-price sensitivity for the recycled material $\left(\omega<\beta_{r}\right)$

$\delta_{i}$ : market share of the recycler $i \quad\left(0<\delta_{i}<1\right.$ and $\left.\sum_{i} \delta_{i}=1\right)$

Functions

$D$ : demand faced by the manufacturer

$D_{m i}$ : quantity ordered by the manufacturer to the recycler $i$

$D_{r i}$ : quantity ordered by the recycler $i$ to the collector

\author{
$\Pi_{m}:$ manufacturer's profit \\ $\Pi_{c}$ : collector's profit \\ $\Pi_{r i}$ : recycler $i$ 's profit
}

3.2. Assumptions. In this study, pricing and ordering decisions are investigated on the waste recycling process of a three-echelon CLSC. The proposed CLSC consists of one monopolistic manufacturer, one monopolistic collector, and two duopolistic recyclers. Figure 1 depicts the overall configuration and the material and cash flows of the investigated supply chain.

The manufacturer produces finished products which are made mainly from recycled wastes. In other words, the manufacturer uses the recycled (raw) materials to produce the product. This assumption is reasonable because, in practice, $100 \%$ recycled products are now being sold in the market. For example, Apple's MacBook Air is made with $100 \%$ recycled aluminum. Seventh Generation released paper towels made from $100 \%$ recycled paper. In addition, $100 \%$ recycled products are found in many remanufacturing industries such as footwear (Allbirds), plastic bottle (Rothy's), watches (Wewood), and clothing and accessories (Cotopaxi, Recover Brands, and Looptworks) [45]. It was reported that Looptworks significantly reduces the amount of garbage in the region and minimizes carbon emissions by working with those who gather manufacturing materials from landfills.

The manufacturer purchases the recycled materials only from the recyclers. Unlike Jafari et al. [20] and Giri and Dey [34], we assume that the manufacturer is not in charge of recycling the wastes. Hence, the manufacturer can obtain the recycled materials directly from the recyclers and then produce the finished product. Under the considered supply chain, the market demand for the finished product is determined based on the final price charged by the manufacturer to consumers in the market. We assume that the market demand, $D$, for the finished product is a linear function of the selling price, $P_{m}$, set by the manufacturer. We take $D=\alpha-\beta_{m} P_{m}$, where $\alpha$ and $\beta_{m}$ indicate the potential market demand and the price sensitivity of the finished product, respectively. We assume that $\alpha, \beta_{m}>0$ and $D>0$.

The recycler's main activities are to purchase the recyclable waste from the collector and provide the manufacturer with the recycled materials. We assume that there are two competing recyclers operating their own recycling facilities. The two recyclers sell identical recycled materials to the manufacturer. We equivalently index the two recyclers by $i=1,2$. Each recycler is assumed to employ a uniform pricing strategy to attract the manufacturer. Thus, the demand of the recycled materials is price-dependent and is assumed to be a decreasing linear function of the price. Let $D_{m i}$ denote the demand function of recycler $i$. Then, $D_{m i}$ has the form of

$$
D_{m i}=\delta_{i} \gamma D-\beta_{r} P_{r i}+\omega P_{r j}>0, \quad i=1,2 j=3-i,
$$

where, $\delta_{i}, \gamma$, and $P_{r i}$ indicate recycler $i$ 's market share of recycling, the quantity of recycled materials required to produce one unit of the finished product, and the price 


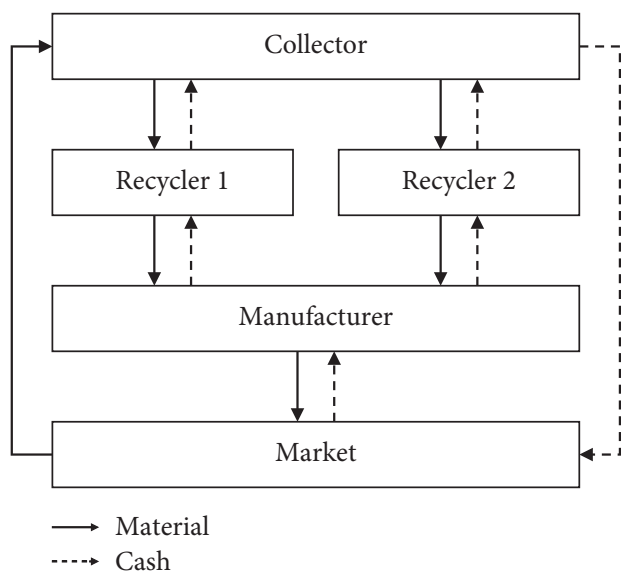

FIgUre 1: Material and cash flow diagram in the closed-loop supply chain with duopolistic recyclers.

offered by recycler $i$, respectively. In equation (1), $\beta_{r}$ represents the manufacturer's price sensitivity with regard to the recycled materials. The term $\omega$ is the cross-price sensitivity, which reflects the degree of cannibalization between the two competing recyclers. In other words, $\omega$ represents the leakage of the demand from one recycler to the other recycler. Therefore, the term $\omega$ is a competition parameter between the two recyclers. As $\omega$ increases, the price competition between the two recyclers in the supply chain becomes more intense. Throughout the paper, it is assumed that $\beta_{r}>\omega$. The linear type of the demand function considering the price competition is assumed in most studies [20,34, 39, 46, 47].

The collector is responsible for collecting waste in the form of end-of-life products from consumers. The collected waste can be classified as either recyclable or nonrecyclable, and the collector transfers the recyclable waste to the recyclers. In this study, the recyclability degree of the waste is also considered; i.e., it is assumed that only a constant share of the waste remains after the recycling process operated by the recyclers. Let $D_{r i}$ denote the ordering quantity of recycler $i$ for the recyclable waste to the collector. Then, $D_{r i}$ is simply given by $D_{r i}=(1 / \theta) D_{m i}>0$ for $i=1,2$, where the term $\theta$ indicates the recyclability degree of the waste. Therefore, the function of the collector's total demand becomes $\sum_{i} D_{r i}>0$.

Based on the demand functions of the participants in the CLSC considered here, the profit function of each participant is obtained by the following equation:

$$
\begin{aligned}
\Pi_{m} & =\left(P_{m}-C_{p}\right) D-\sum_{i} P_{r i} D_{m i}, \\
\Pi_{r i} & =P_{r i} D_{m i}-\left(P_{c}+C_{r i}\right) D_{r i}, \quad i=1,2, \\
\Pi_{c} & =\sum_{i}\left(P_{c}-C_{c}\right) D_{r i},
\end{aligned}
$$

where $\Pi_{m}, \Pi_{r i}$, and $\Pi_{c}$ denote the profits of the manufacturer, the recycler $i$, and the collector, respectively. Note that it is useless to study pricing decisions with no positive profits of participants in practice; therefore, the following assumption must be made: $\Pi_{m}>0, \Pi_{r i}>0$, and $\Pi_{c}>0$.

3.3. Decision-Making Structure. This study utilizes game theory to model the problem of determining the equilibrium prices of the participants in the investigated CLSC. The players participating in the six pricing game models (which are described in the next section) are the manufacturer, the collector, recycler 1 , and recycler 2 . These four players are divided into two groups: the leaders group and the followers group. We assume that the manufacturer and the collector belong to the leaders group and that the two recyclers belong to the followers group. The basic structure of the pricing game model is as follows. The leaders group initially determines the prices devised by the collector and the manufacturer, after which the followers group determines those devised by the two recyclers. This assumption is reasonable because, in our setting, there exists price competition between the two recyclers, and they are under pressure from the collector and manufacturer with regard to the demand for recyclable waste and the supply of recycled materials, respectively. Therefore, the decision power of the leaders group is greater than that of the followers group.
In the leaders group, we deal with two pricing structure types: Stackelberg and Nash. In the Stackelberg pricing structure, the manufacturer acts as the Stackelberg game leader and the collector reacts as the follower [48]. In the Stackelberg pricing structure, the manufacturer initializes the selling price for the finished product and the collector then decides on the selling price for the recyclable waste based on the manufacturer's price. In the game theory literature, a Nash game is a simultaneous-move game in which the manufacturer and the collector make their decisions simultaneously [49]. In the followers group, we deal with three types of competition behavior: Collusion, Cournot, and Stackelberg. When engaging in Collusion behavior, the recyclers cooperatively decide on their selling prices, while their selling prices are set competitively when displaying Cournot behavior [50]. When using Stackelberg behavior, the leader of the two recyclers initially sets the price, after which the follower determines its own price based on the leader's price. Without a loss of generality, we assume that recycler 1 (recycler 2) is a leader (follower) throughout the paper. Therefore, with the two aforementioned pricing structures in the leaders group and the three types of competition behavior in the followers group, six combinations of different pricing game models can be investigated: (i) NashCollusion, (ii) Nash-Cournot, (iii) Nash-Stackelberg, (iv) Stackelberg-Collusion, (v) Stackelberg-Cournot, and (vi) Stackelberg-Stackelberg. Figure 2 illustrates the six different 


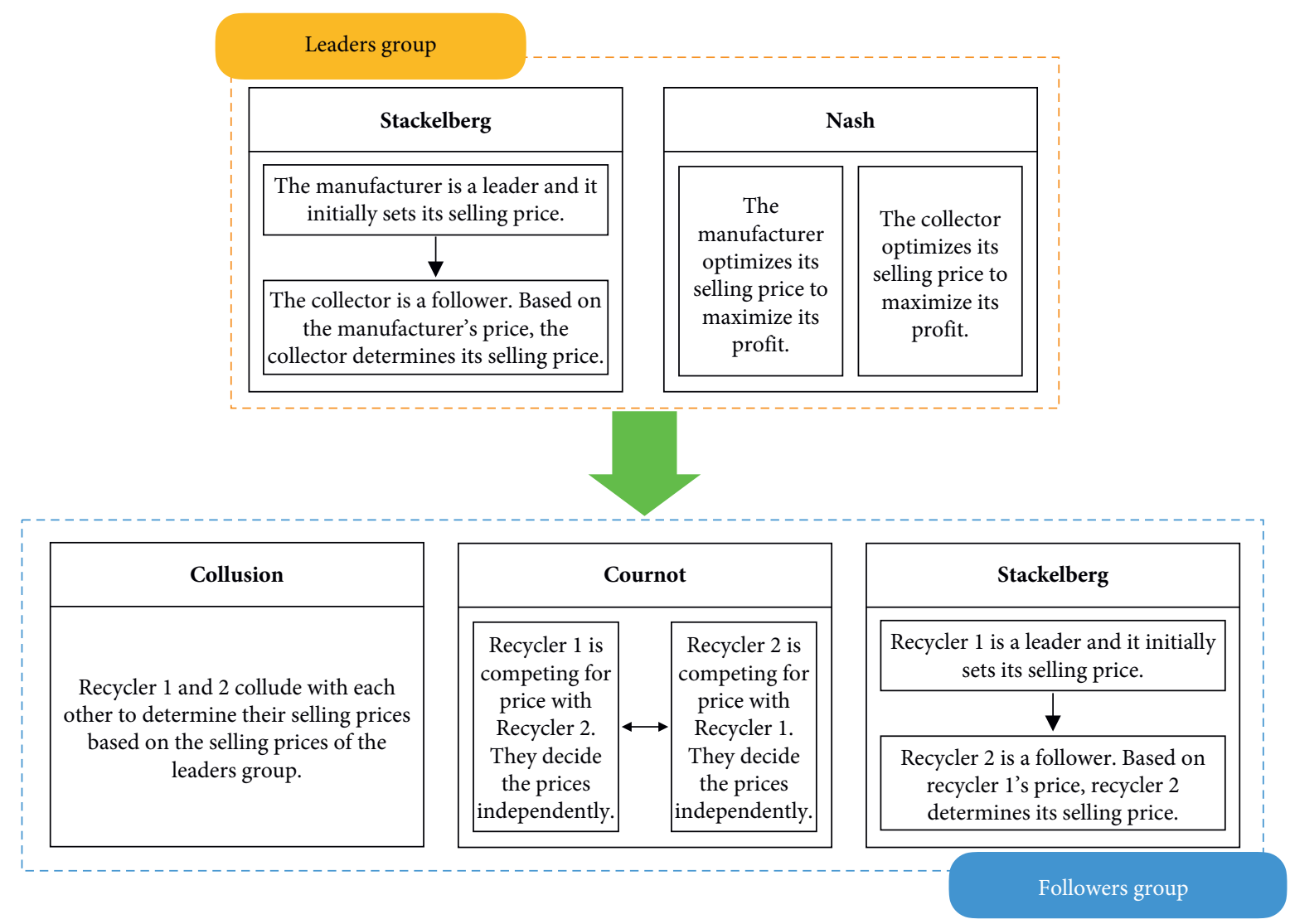

FIGURE 2: Conceptual framework of pricing game models in the dual-channel recycling supply chain.

pricing game models. In the next sections, we develop the mathematical programming and prove the uniqueness of the four players' prices for each pricing game model.

\section{Preliminaries: Pricing Behaviors in the Followers Group}

In this section, we discuss the three competition behaviors of the recyclers in the followers group and obtain the preliminary results for the next section.

4.1. Collusion Behavior in the Followers Group. In the Collusion behavior, the recyclers collude with each other to set their prices for recycled materials. More specifically, the Collusion behavior is similar to the case in which the two recyclers recognize their interdependence and agree to act in union in order to maximize the total profit of the recycling market. Note that the two recyclers cooperate in pricing but still compete in selling. The total profit of the recyclers, $\Pi_{r t}$, in the Collusion behavior can be formulated as follows: $\Pi_{r t}=\Pi_{r 1}+\Pi_{r 2}$. Hence, the recyclers' pricing problem, $\mathrm{RP}^{\mathrm{CL}}$ in the Collusion behavior can be formulated as follows:

$$
\begin{aligned}
& \mathrm{RP}^{\mathrm{CL}} \text {. } \\
& \begin{array}{cl}
\max _{\left(P_{r 1}, P_{r 2}\right) \in \mathbb{R}_{+}^{2}} & \Pi_{r t}\left(P_{r 1}, P_{r 2}\right)=\sum_{i}\left(P_{r i} D_{m i}\right)-\left(P_{c}+C_{r i}\right) D_{r i} \\
\text { s.t. } & \Pi_{r t}\left(P_{r 1}, P_{r 2}\right)>0 .
\end{array}
\end{aligned}
$$

For the recyclers' equilibrium prices, we have the following proposition.

Proposition 1. Given the values of the manufacturer's price, $P_{m}$ and the collector's price $P_{c}$, in the Collusion behavior, there exists a unique equilibrium under the recycler i's price, $P_{r i}^{C L}$ :

$$
P_{r i}^{\mathrm{CL}}=\frac{P_{c}+C_{r i}}{2 \theta}+\frac{K\left(\beta_{r} \delta_{i}+\omega \delta_{j}\right)}{2 \theta\left(\beta_{r}^{2}-\omega^{2}\right)}, \quad \text { for } i=1,2, j=3-i
$$

where $K=\gamma \theta\left(\alpha-\beta_{m} P_{m}\right)$.

Proof. We consider the following Hessian matrix of the objective function in $R P^{C L}$ :

$$
\mathbf{H}_{r}^{\mathrm{CL}}=\left[\begin{array}{cc}
\frac{\partial^{2} \Pi_{r t}}{\partial P_{r 1}^{2}} & \frac{\partial^{2} \Pi_{r t}}{\partial P_{r 1} \partial P_{r 2}} \\
\frac{\partial^{2} \Pi_{r t}}{\partial P_{r 2} \partial P_{r 1}} & \frac{\partial^{2} \Pi_{r t}}{\partial P_{r 2}^{2}}
\end{array}\right]=\left[\begin{array}{cc}
-2 \beta_{r} & \omega \\
\omega & -2 \beta_{r}
\end{array}\right] .
$$

We define $\Delta_{k}^{C L}$ as the leading principal minor of order $k$ in $\mathbf{H}_{r}^{C L}$. We then find that $\Delta_{1}^{C L}=-2 \beta_{r}<0$ and $\Delta_{2}^{\mathrm{SCL}}=4 \beta_{r}^{2}-$ $\omega^{2}>0$ because we assume that $\beta_{r}>\omega$. Therefore, $\mathbf{H}_{r}^{\mathrm{CL}}{ }^{r}$ is negatively definite, implying that $\Pi_{r t}$ is strictly concave in the feasible region and that the stationary point of $\Pi_{r t}$ becomes the global maximizer of $\mathrm{RP}^{\mathrm{CL}}$. Consequently, given 
the competitor's price, each recycler can find its own pricing strategy by setting $\partial \Pi_{r t} / \partial P_{r i}=0$ for $i=1,2$ :

$$
\begin{aligned}
& P_{r 1}=\frac{\beta_{r}\left(P_{c}+C_{r 1}\right)-\omega\left(P_{c}+C_{r 2}\right)+2 \theta \omega P_{r 2}+K \delta_{1}}{2 \beta_{r} \theta}, \\
& P_{r 2}=\frac{\beta_{r}\left(P_{c}+C_{r 2}\right)-\omega\left(P_{c}+C_{r 1}\right)+2 \theta \omega P_{r 1}+K \delta_{2}}{2 \beta_{r} \theta} .
\end{aligned}
$$

Solving the equations system in equation (6) leads to equation (4). This completes the proof.

4.2. Cournot Behavior in the Followers Group. The Cournot behavior forces the recyclers to decide on their prices simultaneously. In other words, each recycler independently sets its price by assuming its competitor's selling price as a parameter. Hence, recycler $i$ 's pricing problem, $\mathrm{RP}_{i}^{\mathrm{CT}}$, considering price competition is modeled as follows:

$$
\begin{aligned}
& \mathrm{RP}_{i}^{\mathrm{CT}}: \max _{P_{r i} \in \mathbb{R}_{+}} \Pi_{r i}\left(P_{r i}\right)=P_{r i} D_{m i}-\left(P_{c}+C_{r i}\right) D_{r i} \\
& \text { s.t. } \Pi_{r i}\left(P_{r i}\right)>0 .
\end{aligned}
$$

For the recyclers' equilibrium prices, we have the following proposition.

Proposition 2. Given the values of $P_{m}$ and $P_{c}$, in the Cournot behavior, there exists a unique equilibrium under the recycler i's price, $P_{r i}^{C T}$ :

$$
P_{r i}^{\mathrm{CT}}=\frac{K\left(2 \beta_{r} \delta_{i}+\omega \delta_{j}\right)+\beta_{r}\left[2 \beta_{r}\left(P_{c}+C_{r i}\right)+\omega\left(P_{c}+C_{r j}\right)\right]}{\theta\left(4 \beta_{r}^{2}-\omega^{2}\right)},
$$

$$
\text { for } i=1,2, j=3-i \text {. }
$$

Proof. The second-order derivative of the objective function in $\mathrm{RP}_{i}^{\mathrm{CT}}$ is given by $\partial^{2} \Pi_{r i} / \partial P_{r i}^{2}=-2 \beta_{r}<0$, for $i=1,2$. Hence, each recycler's profit function is strictly concave on its own decision and there exists a unique equilibrium price for each recycler. Consequently, given the competitor's price, each recycler can find its own pricing strategy by setting $\partial \Pi_{r i} / \partial P_{r i}=0$ for $i=1,2$ :

$$
\begin{aligned}
& P_{r 1}=\frac{\beta_{r}\left(P_{c}+C_{r 1}\right)+\theta \omega P_{r 2}+K \delta_{1}}{2 \theta \beta_{r}}, \\
& P_{r 2}=\frac{\beta_{r}\left(P_{c}+C_{r 2}\right)+\theta \omega P_{r 1}+K \delta_{2}}{2 \theta \beta_{r}} .
\end{aligned}
$$

Solving the equations system in equation (9) leads to equation (8). This completes the proof.

4.3. Stackelberg Behavior in the Followers Group. In the Stackelberg behavior, also known as a sequential game, the leader of the game initially sets the price and the follower then determines its own price based on the leader's price. As noted in Section 3, we assume that recycler 1 acts as the Stackelberg leader while recycler 2 acts as the Stackelberg follower. With this assumption, recycler 1's decision power and market share are greater than those of recycler 2 . Accordingly, it is natural to assume that $\delta_{1} \geq \delta_{2}$. Then, recycler $i$ 's pricing model, $\mathrm{RP}_{i}^{S \mathrm{~T}}$, in the Stackelberg behavior is modeled as follows:

$$
\begin{array}{lll}
\mathrm{RP}_{2}^{\mathrm{ST}}: & \max _{P_{r 2} \in \mathbb{R}_{+}} & \Pi_{r 2}\left(P_{r 2}\right)=P_{r 2} D_{m 2}-\left(P_{c}+C_{r 2}\right) D_{r 2} \\
& \text { s.t. } & \Pi_{r 2}\left(P_{r 2}\right)>0, \\
\mathrm{RP}_{1}^{\mathrm{ST}}: & \max _{P_{r 1} \in \mathbb{R}_{+}} & \Pi_{r 1}\left(P_{r 1}\right)=P_{r 1} D_{m 1}-\left(P_{c}+C_{r 1}\right) D_{r 1} \\
& \text { s.t. } & P_{r 2} \in \arg \max \Pi_{r 2}\left(P_{r 2}\right) \\
& & \Pi_{r 1}\left(P_{r 1}\right)>0 .
\end{array}
$$

For the sequential game above, we have the following proposition.

Proposition 3. Given the values of $P_{m}$ and $P_{c}$, in the Stackelberg behavior, there exists a unique equilibrium under recycler i's price, $P_{r i}^{S T}$ :

$$
\begin{aligned}
& P_{r 1}^{S T}=\frac{P_{c}+C_{r 1}}{2 \theta}+\frac{\beta_{r} \omega\left(P_{c}+C_{r 2}\right)+K\left(2 \beta_{r} \delta_{1}+\omega \delta_{2}\right)}{2 \theta\left(2 \beta_{r}^{2}-\omega^{2}\right)}, \\
& P_{r 2}^{S T}=\frac{\omega P_{r 1}^{S T}}{2 \beta_{r}}+\frac{P_{c}+C_{r 2}}{2 \theta}+\frac{K \delta_{2}}{2 \theta \beta_{r}} .
\end{aligned}
$$

Proof. The second-order derivative of the objective function in $\mathrm{RP}_{2}^{\mathrm{ST}}$ is given by $\partial^{2} \Pi_{r 2} / \partial P_{r 2}^{2}=-2 \beta_{r}<0$. Therefore, $\Pi_{r 2}$ is strictly concave with respect to (w.r.t.) $P_{r 2}$ and, by solving $\partial \Pi_{r 2} / \partial P_{r 2}=0$, the global maximizer of $\Pi_{r 2}$ is obtained as

$$
P_{r 2}^{\mathrm{ST}}=\frac{\omega P_{r 1}}{2 \beta_{r}}+\frac{P_{c}+C_{r 2}}{2 \theta}+\frac{K \delta_{2}}{2 \theta \beta_{r}} \text {. }
$$

By integrating $P_{r 2}^{\mathrm{ST}}$ in equation (12) into $\mathrm{RP}_{1}^{\mathrm{ST}}$, it follows that $\partial^{2} \Pi_{r 1} / \partial P_{r 1}^{2}=-\left(2 \beta_{r}^{2}-\omega^{2}\right) / \beta_{r}<0$. Hence, $\Pi_{r 1}$ is also strictly concave w.r.t, $P_{r 1}$ and, by solving $\partial \Pi_{r 1} / \partial P_{r 1}=0$, the equilibrium solution of $R P_{1}^{S T}$ is given by

$$
P_{r 1}^{\mathrm{ST}}=\frac{P_{c}+C_{r 1}}{2 \theta}+\frac{\beta_{r} \omega\left(P_{c}+C_{r 2}\right)+K\left(2 \beta_{r} \delta_{1}+\omega \delta_{2}\right)}{2 \theta\left(2 \beta_{r}^{2}-\omega^{2}\right)} .
$$

This completes the proof.

\section{Development of the Six Pricing Game Models}

In this section, we present the main results of this paper. Six different pricing game models are carefully analyzed one by one.

5.1. Nash Game Structure in the Leaders Group. The Nash game structure is a simultaneous-move game in which the manufacturer and the collector make their decisions simultaneously.

5.1.1. Nash-Collusion Model. In the Nash-Collusion game model, which is denoted by NCL, a Nash game is played 
between the collector and the manufacturer, while the recyclers collude with each other to set the prices for recycled materials. In the first stage of the NCL model, the manufacturer and the collector announce their sales prices simultaneously. Based on this, in the second stage, the recyclers cooperate in terms of pricing with each other and set their prices to maximize the sum of their profits. According to Proposition 1, we know that the total profit of the recyclers, $\Pi_{r t}$ is strictly concave with respect to the recyclers' prices, $P_{r 1}$ and $P_{r 2}$, and the equilibrium price of recycler $i$ in the NCL model is expressed as

$$
P_{r i}^{\mathrm{NCL}}=\frac{P_{c}+C_{r i}}{2 \theta}+\frac{K\left(\beta_{r} \delta_{i}+\omega \delta_{j}\right)}{2 \theta\left(\beta_{r}^{2}-\omega^{2}\right)}, \quad \text { for } i=1,2, j=3-i .
$$

With recyclers' prices in equation (14), the collector's pricing problem, $C P^{\mathrm{NCL}}$, and the manufacturer's pricing problem, $M P^{\mathrm{NCL}}$, are formulated as follows:

$$
\begin{array}{rll}
C P^{N C L}: \max _{P_{c} \in \mathbb{R}_{+}} & \Pi_{c}\left(P_{c}\right)=\sum_{i}\left(P_{c}-C_{c}\right) D_{r i} \\
\text { s.t. } \quad & \text { eq. }(14) \\
& & \Pi_{c}\left(P_{c}\right)>0, \\
M P^{N C L}: \quad \max _{P_{m} \in \mathbb{R}_{+}} & \Pi_{m}\left(P_{m}\right)=\left(P_{m}-C_{p}\right) D-\sum_{i} P_{r i} D_{m i} \\
\text { s.t. } \quad & \text { eq. }(14) \\
& \Pi_{m}\left(P_{m}\right)>0 .
\end{array}
$$

Proposition 4 states the result of the NCL pricing game model.

Proposition 4. In the Nash-Collusion pricing game model, there exists a unique Nash equilibrium under the collector's price, $P_{c}^{N C L}$, and the manufacturer's price, $P_{m}^{N C L}$ :

$$
\begin{aligned}
& P_{c}^{\mathrm{NCL}}=\frac{2 C_{c}-C_{r 1}-C_{r 2}}{4}+\frac{\gamma \theta\left(\alpha-\beta_{m} C_{p}\right)\left(\beta_{r}+\omega\right)}{8\left(\beta_{r}^{2}-\omega^{2}\right)+2 \gamma^{2} \beta_{m}\left(2 \omega \delta_{1} \delta_{2}+\beta_{r} \sum_{i} \delta_{i}^{2}\right)}, \\
& P_{m}^{\mathrm{NCL}}=\frac{\alpha}{\beta_{m}}-\frac{2\left(\alpha-\beta_{m} C_{p}\right)\left(\beta_{r}^{2}-\omega^{2}\right)}{4 \beta_{m}\left(\beta_{r}^{2}-\omega^{2}\right)+\gamma^{2} \beta_{m}^{2}\left(2 \omega \delta_{1} \delta_{2}+\beta_{r} \sum_{i} \delta_{i}^{2}\right)} .
\end{aligned}
$$

Proof. From the objective functions in $C P^{\mathrm{NCL}}$ and $M P^{\mathrm{NCL}}$, their second-order derivatives are given by, respectively,

$$
\begin{aligned}
\frac{\partial^{2} \Pi_{c}}{\partial P_{c}^{2}} & =-\frac{2\left(\beta_{r}-\omega\right)}{\theta^{2}}<0, \\
\frac{\partial^{2} \Pi_{m}}{\partial P_{m}^{2}} & =-\beta_{m}\left[2+\frac{\gamma^{2} \beta_{m}\left(2 \omega \delta_{1} \delta_{2}+\beta_{r} \sum_{i} \delta_{i}^{2}\right)}{2\left(\beta_{r}^{2}-\omega^{2}\right)}\right]<0 .
\end{aligned}
$$

Therefore, the collector's and the manufacturer's profit functions are both strictly concave on their own decision variables and there exist unique equilibrium prices for the collector and the manufacturer. Consequently, the collector and the manufacturer can find their own pricing strategies by solving the first-order conditions of $\partial \Pi_{c} / \partial P_{c}=0$ and $\partial \Pi_{m} / \partial P_{m}=0$ :

$$
\begin{aligned}
P_{c} & =\frac{2 C_{c}-C_{r 1}-C_{r 2}}{4}+\frac{K}{4\left(\beta_{r}-\omega\right)}, \\
P_{m} & =\beta_{m}^{-1}\left[\alpha-\frac{2\left(\alpha-\beta_{m} C_{p}\right)\left(\beta_{r}^{2}-\omega^{2}\right)}{4\left(\beta_{r}^{2}-\omega^{2}\right)+\gamma^{2} \beta_{m}\left(2 \omega \delta_{1} \delta_{2}+\beta_{r} \sum_{i} \delta_{i}^{2}\right)}\right] .
\end{aligned}
$$

Solving equation (18) simultaneously leads to equation (16). This completes the proof.

By the backward induction, the equilibrium prices of the recyclers in the NCL model are determined as follows:

$$
\begin{array}{r}
P_{r i}^{\mathrm{NCL}}=\frac{P_{c}^{\mathrm{NCL}}+C_{r i}}{2 \theta}+\frac{\gamma \theta\left(\alpha-\beta_{m} P_{m}^{\mathrm{NCL}}\right)\left(\beta_{r} \delta_{i}+\omega \delta_{j}\right)}{2 \theta\left(\beta_{r}^{2}-\omega^{2}\right)}, \\
\text { for } i=1,2, j=3-i .
\end{array}
$$

5.1.2. Nash-Cournot Model. In the Nash-Cournot game model, which is denoted by NCT, a Nash game is played between the collector and the manufacturer, with the Cournot behavior displayed by the two recyclers. In the first stage of the NCT model, the manufacturer and the collector announce their sales prices simultaneously. Based on this, in the second stage, the equilibrium prices of the two recyclers are simultaneously and independently obtained. According to Proposition 2, the equilibrium price of recycler $i$ in the NCT model is expressed as

$$
\begin{array}{r}
P_{r i}^{\mathrm{NCT}}=\frac{K\left(2 \beta_{r} \delta_{i}+\omega \delta_{j}\right)+\beta_{r}\left[2 \beta_{r}\left(P_{c}+C_{r i}\right)+\omega\left(P_{c}+C_{r j}\right)\right]}{\theta\left(4 \beta_{r}^{2}-\omega^{2}\right)}, \\
\text { for } i=1,2, j=3-i .
\end{array}
$$

With the recyclers' equilibrium prices in equation (20), the collector's and the manufacturer's pricing games are formulated as follows, respectively,

$$
\begin{array}{rll}
C P^{\mathrm{NCT}}: \max _{P_{c} \in \mathbb{R}_{+}} & \Pi_{c}\left(P_{c}\right)=\sum_{i}\left(P_{c}-C_{c}\right) D_{r i} \\
\text { s.t. } \quad & \text { eq. }(20) \\
& \Pi_{c}\left(P_{c}\right)>0, \\
M P^{\mathrm{NCT}}: \max _{P_{m} \in \mathbb{R}_{+}} & \Pi_{m}\left(P_{m}\right)=\left(P_{m}-C_{p}\right) D-\sum_{i} P_{r i} D_{m i} \\
\text { s.t. } \quad \text { eq. }(20) & \\
& \Pi_{m}\left(P_{m}\right)>0 .
\end{array}
$$

The following proposition pertains to the results of the NCT model.

Proposition 5. In the Nash-Cournot pricing game model, there exists a unique Nash equilibrium under the collector's price, $P_{c}^{N C T}$, and the manufacturer's price, $P_{m}^{N C T}$. 
Proof. From the objective functions in $C P^{\mathrm{NCT}}$ and $M P^{\mathrm{NCT}}$, their second-order derivatives are given, respectively, by

$$
\begin{gathered}
\frac{\partial^{2} \Pi_{c}}{\partial P_{c}^{2}}=-\frac{4 \beta_{r}\left(\beta_{r}-\omega\right)}{\theta^{2}\left(2 \beta_{r}-\omega\right)}<0, \\
\frac{\partial^{2} \Pi_{m}}{\partial P_{m}^{2}}=-2 \beta_{m}\left(1+X_{1}\right)<0,
\end{gathered}
$$

where

$$
X_{1}=\frac{\gamma^{2} \beta_{m} \beta_{r}\left[8 \omega \beta_{r} \delta_{1} \delta_{2}+\left(4 \beta_{r}^{2}-\omega^{2}\right) \sum_{i} \delta_{i}^{2}\right]}{\left(4 \beta_{r}^{2}-\omega^{2}\right)^{2}}>0
$$

Note that the collector's and the manufacturer's profit functions are both strictly concave on their own decision variables. Thus, there exist unique Nash equilibrium prices for the collector and the manufacturer. Consequently, by solving the first-order conditions, $\partial \Pi_{c} / \partial P_{c}=0$ and $\partial \Pi_{m} / \partial P_{m}=0$, the collector's equilibrium price, $P_{c}^{\mathrm{NCT}}$, and the manufacturer's equilibrium price, $P_{m}^{\mathrm{NCT}}$, are obtained. This completes the proof.

The explicit expressions of $P_{c}^{\mathrm{NCT}}$ and $P_{m}^{\mathrm{NCT}}$ are long and complicated. Instead, we present a brief version of the solving procedure of the NCT model in Appendix A.

5.1.3. Nash-Stackelberg Model. In the Nash-Stackelberg game model, which is denoted by NST, a Nash game is played between the collector and the manufacturer, while a Stackelberg game is played between the two recyclers. In the first stage of the NST model, the manufacturer and the collector announce their sales prices simultaneously. Based on this, in the second stage, recycler 1 determines its sales price. In the third stage, following recycler 1's price, recycler 2 makes a further pricing decision. By considering the Stackelberg behavior of the recyclers, their prices are already known as

$$
\begin{aligned}
& P_{r 1}^{\mathrm{NST}}=\frac{P_{c}+C_{r 1}}{2 \theta}+\frac{\beta_{r} \omega\left(P_{c}+C_{r 2}\right)+K\left(2 \beta_{r} \delta_{1}+\omega \delta_{2}\right)}{2 \theta\left(2 \beta_{r}^{2}-\omega^{2}\right)}, \\
& P_{r 2}^{\mathrm{NST}}=\frac{\omega P_{r 1}^{\mathrm{NST}}}{2 \beta_{r}}+\frac{P_{c}+C_{r 2}}{2 \theta}+\frac{K \delta_{2}}{2 \theta \beta_{r}} .
\end{aligned}
$$

Therefore, with (23), the collector's pricing problem, $C P^{\mathrm{NST}}$, and the manufacturer's pricing problem, $M P^{\mathrm{NST}}$, are formulated as follows, respectively,

$$
\begin{aligned}
& C P^{\mathrm{NST}}: \max _{P_{c} \in \mathbb{R}_{+}} \Pi_{c}\left(P_{c}\right)=\sum_{i}\left(P_{c}-C_{c}\right) D_{r i} \\
& \text { s.t. } \quad \text { eq. }(24) \\
& \Pi_{c}\left(P_{c}\right)>0 \text {, } \\
& M P^{\mathrm{NST}}: \max _{P_{m} \in \mathbb{R}_{+}} \Pi_{m}\left(P_{m}\right)=\left(P_{m}-C_{p}\right) D-\sum_{i} P_{r i} D_{m i} \\
& \text { s.t. eq. (24) } \\
& \Pi_{m}\left(P_{m}\right)>0 \text {. }
\end{aligned}
$$

Proposition 6. In the Nash-Stackelberg pricing game model, there exists a unique Nash equilibrium under the collector's price, $P_{c}^{N S T}$, and the manufacturer's price, $P_{m}^{N S T}$.

Proof. The second-order derivative of $\Pi_{c}$ w.r.t. $P_{c}$ is given by

$$
\frac{\partial^{2} \Pi_{c}}{\partial P_{c}^{2}}=-\frac{\left(\beta_{r}-\omega\right)\left[8 \beta_{r}^{3}-\omega^{3}+\beta_{r} \omega\left(4 \beta_{r}-3 \omega\right)\right]}{2 \theta^{2} \beta_{r}\left(2 \beta_{r}^{2}-\omega^{2}\right)} .
$$

From the fact that $\beta_{r}>\omega \Longrightarrow 8 \beta_{r}^{3}>\omega^{3}$ and $4 \beta_{r}>3 \omega$, it is easy to show that $\partial^{2} \Pi_{c} / \partial P_{c}^{2}<0$. Therefore, $\Pi_{c}$ is strictly concave w.r.t. $P_{c}$. The second-order derivative of $\Pi_{m}$ w.r.t. $P_{m}$ is also given by $\partial^{2} \Pi_{m} / \partial P_{m}^{2}=-2 \beta_{m}\left(1+X_{2}\right)$, where model.

Proposition 6 states the result of the NST pricing game

$$
X_{2}=\frac{\gamma^{2} \beta_{m}\left\{4 \beta_{r}^{2}\left[\delta_{1}^{2}\left(2 \beta_{r}^{2}-\omega^{2}\right)+\delta_{2}^{2}\left(4 \beta_{r}^{2}-\omega^{2}\right)\right]+4 \beta_{r} \omega \delta_{1} \delta_{2}\left(8 \beta_{r}^{2}-\omega^{2}\right)+8 \beta_{r}^{4} \delta_{1}^{2}-\omega^{4} \delta_{2}^{2}\right\}}{16 \beta_{r}\left(2 \beta_{r}^{2}-\omega^{2}\right)^{2}}
$$

Upon the assumption that $\delta_{1} \geq \delta_{2}$, it follows that $8 \beta_{r}^{4} \delta_{1}^{2}-\omega^{4} \delta_{2}^{2} \geq \delta_{2}^{2}\left(8 \beta_{r}^{4}-\omega^{4}\right)>0$. Therefore, we have the following relationship: $\delta_{1} \geq \delta_{2} \Longrightarrow X_{2}>0 \Longrightarrow \partial^{2} \Pi_{m} / \partial P_{m}^{2}<0$. Thus, $\Pi_{m}$ is also strictly concave w.r.t. $P_{m}$ and there exist unique Nash equilibrium prices for the collector and the manufacturer. Consequently, by solving the first-order conditions, $\partial \Pi_{c} / \partial P_{c}=0$ and $\partial \Pi_{m} / \partial P_{m}=0$, the collector's equilibrium price, $P_{c}^{\mathrm{NST}}$, and the manufacturer's equilibrium price, $P_{m}^{\mathrm{NST}}$, are obtained. This completes the proof.

The explicit expressions of $P_{c}^{\mathrm{NST}}$ and $P_{m}^{\mathrm{NST}}$ are long and complicated. Instead, we present a brief version of the solving procedure of the NST model in Appendix A. 
5.2. Stackelberg Game Structure in the Leaders Group. In the Stackelberg game structure, the manufacturer acts as a Stackelberg game leader and the collector reacts as the follower.

5.2.1. Stackelberg-Collusion Model. In the Stackelberg-Collusion game model, which is denoted by SCL, a Stackelberg game is played between the collector and the manufacturer, while the recyclers collude with each other to set the prices of recycled materials. In the first stage of the SCL model, the manufacturer announces the selling price for the finished product. Based on this, in the second stage of the game, the collector determines its selling price for the recyclable waste. In the last stage, following the collector's price, two recyclers make a decision on their prices cooperatively. According to Proposition 1 , the recycler $i$ 's equilibrium price, $P_{r i}^{\mathrm{SCL}}$, in the SCL model is given by

$$
P_{r i}^{\mathrm{SCL}}=\frac{P_{c}+C_{r i}}{2 \theta}+\frac{K\left(\beta_{r} \delta_{i}+\omega \delta_{j}\right)}{2 \theta\left(\beta_{r}^{2}-\omega^{2}\right)}, \quad \text { for } i=1,2, j=3-i .
$$

By substituting equation (28) into the collector's profit function, the collector's pricing problem, $C P^{\mathrm{SCL}}$, regarding the SCL model can be formulated as follows:

$$
\begin{array}{lll}
C P^{\text {SCL. }}: & \max _{P_{c} \in \mathbb{R}_{+}} & \Pi_{c}\left(P_{c}\right)=\sum_{i}\left(P_{c}-C_{c}\right) D_{r i} \\
\text { s.t. } & \text { eq. }(28) \\
& \Pi_{c}\left(P_{c}\right)>0 .
\end{array}
$$

Proposition 7. Given the value of $P_{m}$, there exists a unique equilibrium solution, $P_{c}^{S C L}$, which maximizes the collector's profit:

$$
P_{c}^{\mathrm{SCL}}=\frac{2 C_{c}-C_{r 1}-C_{r 2}}{4}+\frac{K}{4\left(\beta_{r}-\omega\right)} .
$$

Proof. The second-order derivative of $\Pi_{c}$ w.r.t. $P_{c}$ can be obtained as $\partial^{2} \Pi_{c} / P_{c}^{2}=-2\left(\beta_{r}-\omega\right) / \theta^{2}<0$. Therefore, the objective function $\Pi_{c}$ in $C P^{\mathrm{SCL}}$ is strictly concave and there exists a unique global maximizer of $C P^{\mathrm{SCL}}$. By setting $\partial \Pi_{c} / \partial P_{c}=0$, we obtain the equilibrium solution $P_{c}^{\mathrm{SCL}}$ in equation (30). This completes the proof.

Accordingly, by substituting equations (28) and (30) into the manufacturer's profit function, the manufacturer's pricing problem, $M P^{\mathrm{SCL}}$, regarding the SCL model can be formulated as follows:

$$
\begin{aligned}
& M P^{\mathrm{SCL}}: \quad \max _{P_{m} \in \mathbb{R}_{+}} \Pi_{m}\left(P_{m}\right)=\left(P_{m}-C_{p}\right) D-\sum_{i} P_{r i} D_{m i} \\
& \text { s.t. } \quad \text { eqs. }(28) \text { and (30) } \\
& \Pi_{m}\left(P_{m}\right)>0 \text {. }
\end{aligned}
$$

Proposition 8. In the Stackelberg-Collusion pricing game model, there exists a unique Stackelberg equilibrium under the manufacturer's price, $P_{m}^{S C L}$ :

$$
P_{m}^{\mathrm{SCL}}=\frac{\left(\beta_{r}^{2}-\omega^{2}\right)\left[\gamma \beta_{m}\left(2 C_{c}+C_{r 1}+C_{r 2}\right)-16 \theta\left(\alpha+\beta_{m} C_{p}\right)\right]+\alpha \gamma^{2} \theta \beta_{m}\left[16 \delta_{1} \delta_{2}\left(\beta_{r}-\omega\right)-7 \beta_{r}+\omega\right]}{\theta \beta_{m}\left\{\gamma^{2} \beta_{m}\left[16 \delta_{1} \delta_{2}\left(\beta_{r}-\omega\right)-7 \beta_{r}+\omega\right]-32\left(\beta_{r}^{2}-\omega^{2}\right)\right\}} .
$$

Proof. The second-order derivative of $\Pi_{m}$ w.r.t. $P_{m}$ can be obtained as

$$
\frac{\partial^{2} \Pi_{m}}{\partial P_{m}^{2}}=\beta_{m}\left\{\frac{\gamma^{2} \beta_{m}\left[16 \delta_{1} \delta_{2}\left(\beta_{r}-\omega\right)-7 \beta_{r}+\omega\right]}{16\left(\beta_{r}^{2}-\omega^{2}\right)}-2\right\}
$$

If the condition $\partial^{2} \Pi_{m} / \partial P_{m}^{2}<0$ is satisfied, the objective function in $M P^{\mathrm{SCL}}$ is strictly concave and there exists a unique global maximizer of $M P^{\mathrm{SCL}}$. Because $0 \leq \delta_{1}, \delta_{2} \leq 1$, and $\delta_{1}+\delta_{2}=1$, the maximum value of $\delta_{1} \delta_{2}$ must be 0.25 , where $\delta_{1}=\delta_{2}=0.5$. The upper bound of $\partial^{2} \Pi_{m} / \partial P_{m}^{2}$ is obtained as follows:

$$
\begin{aligned}
\frac{\partial^{2} \Pi_{m}}{\partial P_{m}^{2}} & =\beta_{m}\left\{\frac{\gamma^{2} \beta_{m}\left[16 \delta_{1} \delta_{2}\left(\beta_{r}-\omega\right)-7 \beta_{r}+\omega\right]}{16\left(\beta_{r}^{2}-\omega^{2}\right)}-2\right\} \\
& \leq \beta_{m}\left\{\frac{\gamma^{2} \beta_{m}\left[4\left(\beta_{r}-\omega\right)-7 \beta_{r}+\omega\right]}{16\left(\beta_{r}^{2}-\omega^{2}\right)}-2\right\} \\
& =-\beta_{m}\left[\frac{3 \gamma^{2} \beta_{m}}{16\left(\beta_{r}-\omega\right)}+2\right] .
\end{aligned}
$$

Therefore, it is obvious that $\partial^{2} \Pi_{m} / \partial P_{m}^{2}<0$. From the first-order condition, $\partial \Pi_{m} / \partial P_{m}=0$, we can obtain the 
manufacturer's equilibrium solution $P_{m}^{\mathrm{SCL}}$ in equation (32). This completes the proof.

Hence, considering the backward induction, the equilibrium prices of the collector and the recyclers in the SCL model are determined as follows:

$$
\begin{aligned}
P_{c}^{\mathrm{SCL}} & =\frac{2 C_{c}-C_{r 1}-C_{r 2}}{4}+\frac{\gamma \theta\left(\alpha-\beta_{m} P_{m}^{\mathrm{SCL}}\right)}{4\left(\beta_{r}-\omega\right)}, \\
P_{r 1}^{\mathrm{SCL}} & =\frac{\gamma \theta\left(\alpha-\beta_{m} P_{m}^{\mathrm{SCL}}\right)\left(\beta_{r} \delta_{1}+\omega \delta_{2}\right)+\left(\beta_{r}^{2}-\omega^{2}\right)\left(P_{c}^{\mathrm{SCL}}+C_{r 1}\right)}{2 \theta\left(\beta_{r}^{2}-\omega^{2}\right)}, \\
P_{r 2}^{\mathrm{SCL}} & =\frac{\gamma \theta\left(\alpha-\beta_{m} P_{m}^{\mathrm{SCL}}\right)\left(\beta_{r} \delta_{2}+\omega \delta_{1}\right)+\left(\beta_{r}^{2}-\omega^{2}\right)\left(P_{c}^{S C L}+C_{r 2}\right)}{2 \theta\left(\beta_{r}^{2}-\omega^{2}\right)} .
\end{aligned}
$$

5.2.2. Stackelberg-Cournot Model. In the StackelbergCournot game model, which is denoted by SCT, a Stackelberg game is played between the collector and the manufacturer, with the Cournot behavior following the two recyclers. In the first stage of the SCT model, the manufacturer announces the selling price for the finished product. Based on this, in the second stage game, the collector determines its selling price for the recyclable waste. In the last stage, following the collector's price, each recycler reaches a price decision independently. According to Proposition 2, recycler $i$ 's equilibrium price, $P_{r i}^{S C T}$, in the SCT model is given by

$$
\begin{array}{r}
P_{r i}^{\mathrm{SCT}}=\frac{K\left(2 \beta_{r} \delta_{i}+\omega \delta_{j}\right)+\beta_{r}\left[2 \beta_{r}\left(P_{c}+C_{r i}\right)+\omega\left(P_{c}+C_{r j}\right)\right]}{\theta\left(4 \beta_{r}^{2}-\omega^{2}\right)}, \\
\text { for } i=1,2, j=3-i .
\end{array}
$$

Then, by replacing equation (36) into the collector's profit function, the collector's pricing problem, $C P^{S C T}$, regarding the SCT model can be formulated as follows:

$$
\begin{aligned}
& C P^{\mathrm{SCT}}: \max _{P_{c} \in \mathbb{R}_{+}} \Pi_{c}\left(P_{c}\right)=\sum_{i}\left(P_{c}-C_{c}\right) D_{r i} \\
& \text { s.t. eq. (36) } \\
& \Pi_{c}\left(P_{c}\right)>0 \text {. }
\end{aligned}
$$

Proposition 9. Given the value of $P_{m}$, there exists a unique equilibrium solution, $P_{c}^{S C T}$, which maximizes the collector's profit:

$$
P_{c}^{\mathrm{SCT}}=\frac{2 C_{c}-C_{r 1}-C_{r 2}}{4}+\frac{K}{4\left(\beta_{r}-\omega\right)} .
$$

Proof. The second-order derivative of $\Pi_{c}$ w.r.t. $P_{c}$ can be obtained as $\partial^{2} \Pi_{c} / \partial P_{c}^{2}=-4 \beta_{r}\left(\beta_{r}-\omega\right) / \theta^{2}\left(2 \beta_{r}-\omega\right)<0$. Therefore, the objective function $\Pi_{c}$ in $C P^{\mathrm{SCT}}$ is strictly concave and there exists a unique global maximizer of
$C P^{\mathrm{SCT}}$. By setting $\partial \Pi_{c} / \partial P_{c}=0$, we obtain the equilibrium solution $P_{c}^{\text {SCT }}$ in equation (38). This completes the proof.

Ultimately, by integrating equations (36) and (38) into the manufacturer's profit function, the manufacturer's pricing problem, $M P^{\mathrm{SCT}}$, in the SCT model can be formulated as follows:

$$
\begin{aligned}
& M P^{\mathrm{SCT}}: \max _{P_{m} \in \mathbb{R}_{+}} \Pi_{m}\left(P_{m}\right)=\left(P_{m}-C_{p}\right) D-\sum_{i} P_{r i} D_{m i} \\
& \text { s.t. } \quad \text { eqs. }(36) \text { and (38) } \\
& \Pi_{m}\left(P_{m}\right)>0 \text {. }
\end{aligned}
$$

Proposition 10. In the Stackelberg-Cournot pricing game model, there exists a unique Stackelberg equilibrium under the manufacturer's price, $P_{m}^{S C T}$. By solving the first-order condition, $P_{m}^{S C T}$ is obtained.

Proof. The second-order derivative of $\Pi_{m}$ w.r.t. $P_{m}$ can be obtained as

$$
\frac{\partial^{2} \Pi_{m}}{\partial P_{m}^{2}}=\beta_{m}\left[\frac{4 \gamma^{2} \delta_{1} \delta_{2} \beta_{m} \beta_{r}}{\left(2 \beta_{r}+\omega\right)^{2}}+\frac{\gamma^{2} \beta_{m} \beta_{r} X_{3}}{4\left(\beta_{r}-\omega\right)\left(4 \beta_{r}^{2}-\omega^{2}\right)^{2}}-2\right] \text {. }
$$

where $X_{3}=6 \omega^{3}-15 \omega^{2} \beta_{r}+28 \omega \beta_{r}^{2}-28 \beta_{r}^{3}$. If the condition $\partial^{2} \Pi_{m} / \partial P_{m}^{2}<0$ is satisfied, the objective function in $M P^{\mathrm{SCT}}$ is strictly concave and there exists a unique global maximizer of $M P^{\text {SCT }}$. Like the proof of Proposition 8, the upper bound of $\partial^{2} \Pi_{m} / \partial P_{m}^{2}$ is obtained as follows:

$$
\begin{aligned}
\frac{\partial^{2} \Pi_{m}}{\partial P_{m}^{2}} & =\beta_{m}\left[\frac{4 \gamma^{2} \delta_{1} \delta_{2} \beta_{m} \beta_{r}}{\left(2 \beta_{r}+\omega\right)^{2}}+\frac{\gamma^{2} \beta_{m} \beta_{r} X_{3}}{4\left(\beta_{r}-\omega\right)\left(4 \beta_{r}^{2}-\omega^{2}\right)^{2}}-2\right] \\
& \leq \beta_{m}\left[\frac{\gamma^{2} \beta_{m} \beta_{r}}{\left(2 \beta_{r}+\omega\right)^{2}}+\frac{\gamma^{2} \beta_{m} \beta_{r} X_{3}}{4\left(\beta_{r}-\omega\right)\left(4 \beta_{r}^{2}-\omega^{2}\right)^{2}}-2\right] \\
& =-\beta_{m}\left[\frac{\gamma^{2} \beta_{m} \beta_{r}\left(3 \beta_{r}-2 \omega\right)}{4\left(\beta_{r}-\omega\right)\left(2 \beta_{r}-\omega\right)^{2}}+2\right] .
\end{aligned}
$$

Here, it is true that $3 \beta_{r}>2 \omega$ because we assume that $\beta_{r}>\omega$. This implies that

$$
3 \beta_{r}>2 \omega \Longrightarrow \frac{\gamma^{2} \beta_{m} \beta_{r}\left(3 \beta_{r}-2 \omega\right)}{4\left(\beta_{r}-\omega\right)\left(2 \beta_{r}-\omega\right)^{2}}>0 \Longrightarrow \frac{\partial^{2} \Pi_{m}}{\partial P_{m}^{2}}<0 .
$$

Hence, from the first-order condition, $\partial \Pi_{m} / \partial P_{m}=0$, we can obtain the manufacturer's equilibrium solution $P_{m}^{\mathrm{SCT}}$. This completes the proof.

The explicit expression of $P_{m}^{S C T}$ is long and complicated. Instead, we present a brief version of the solving procedure in Appendix B.

5.2.3. Stackelberg-Stackelberg Model. In the StackelbergStackelberg game model, which is denoted by SST, only one 
Stackelberg game is played throughout the investigated supply chain. This Stackelberg game consists of four stages. In the first stage, the manufacturer announces the selling price of the finished product. Based on this, in the second stage of the game, the collector determines its selling price for the recyclable waste. In the third stage, following the collector's selling price, recycler 1 sets the selling price for the recycled materials. Finally, in the last stage, recycler 2 makes a decision on its selling price based on the information on other players' prices. By considering the Stackelberg behavior of the recyclers, their prices are already known as

$$
\begin{aligned}
& P_{r 1}^{\mathrm{SST}}=\frac{P_{c}+C_{r 1}}{2 \theta}+\frac{\beta_{r} \omega\left(P_{c}+C_{r 2}\right)+K\left(2 \beta_{r} \delta_{1}+\omega \delta_{2}\right)}{2 \theta\left(2 \beta_{r}^{2}-\omega^{2}\right)}, \\
& P_{r 2}^{\mathrm{SST}}=\frac{\omega P_{r 1}^{\mathrm{SST}}}{2 \beta_{r}}+\frac{P_{c}+C_{r 2}}{2 \theta}+\frac{K \delta_{2}}{2 \theta \beta_{r}} .
\end{aligned}
$$

Then, by substituting equation (43) into the collector's profit function, the collector's pricing problem, $C P^{S S T}$ regarding the SST model can be formulated as follows:

$$
\begin{aligned}
& C P^{\mathrm{SST}}: \max _{P_{c} \in \mathbb{R}_{+}} \Pi_{c}\left(P_{c}\right)=\sum_{i}\left(P_{c}-C_{c}\right) D_{r i} \\
& \text { s.t. eq. (43) } \\
& \Pi_{c}\left(P_{c}\right)>0 \text {. }
\end{aligned}
$$

Proposition 11. Given the value of $P_{m}$, there exists a unique equilibrium solution, $P_{c}^{S S T}$, which maximizes the collector's profit:

$$
P_{c}^{\mathrm{SST}}=\frac{1}{4}\left\{2 C_{c}-C_{r 1}-C_{r 2}+\frac{K}{\beta_{r}-\omega}+\frac{\omega^{2}\left[K\left(\delta_{2}-\delta_{1}\right)+\left(\beta_{r}+\omega\right)\left(C_{r 1}-C_{r 2}\right)\right]}{8 \beta_{r}^{3}-\omega^{3}+\beta_{r} \omega\left(4 \beta_{r}-3 \omega\right)}\right\} .
$$

Proof. The second-order derivative of $\Pi_{c}$ w.r.t. $P_{c}$ can be obtained as

$$
\frac{\partial^{2} \Pi_{c}}{\partial P_{c}^{2}}=-\frac{\left(\beta_{r}-\omega\right)\left[8 \beta_{r}^{3}-\omega^{3}+\beta_{r} \omega\left(4 \beta_{r}-3 \omega\right)\right]}{2 \theta^{2} \beta_{r}\left(2 \beta_{r}^{2}-\omega^{2}\right)}<0 .
$$

Therefore, the objective function $\Pi_{c}$ in $C P^{\mathrm{SCT}}$ is strictly concave and there exists a unique global maximizer of $C P^{\mathrm{SCS}}$. By setting $\partial \Pi_{c} / \partial P_{c}=0$, we obtain the equilibrium solution $P_{c}^{S C T}$ in equation (45). This completes the proof.

Ultimately, by integrating equations (43) and (45) into the manufacturer's profit function, the manufacturer's pricing problem, $M P^{\mathrm{SST}}$, in the SST model can be formulated as follows:

$$
\begin{array}{rll}
M P^{\mathrm{SST}}: & \max _{P_{m} \in \mathbb{R}_{+}} & \Pi_{m}\left(P_{m}\right)=\left(P_{m}-C_{p}\right) D-\sum_{i} P_{r i} D_{m i} \\
\text { s.t. } & \text { eqs. }(43) \text { and }(45) \\
& \Pi_{m}\left(P_{m}\right)>0 .
\end{array}
$$

For the uniqueness of the manufacturer's equilibrium price, we introduce the following conjecture:

Conjecture 1. The objective function, $\Pi_{m}$, in $M P^{S S T}$ is strictly concave w.r.t. the manufacturer's price, $P_{m}$.

Because the second-order derivative of the manufacturer's profit function has a highly complicated form in terms of input parameters, it is difficult to prove the concavity of the manufacturer's profit function. Instead, we present a simple numerical example to show that Conjecture 1 is reasonable. We set the parameters as follows: $\alpha=500$, $\beta_{m}=4, \beta_{r}=10, \omega=5, \delta_{1}=0.7, \gamma=8, \theta=0.5, C_{p}=1$,
$C_{r 1}=C_{r 2}=0.5$, and $C_{c}=0.2$. In Figure 3, we can observe that $\Pi_{m}$ is strictly concave w.r.t. $P_{m}$, and the maximum is obtained at $P_{m}=115.946$.

Proposition 12. Assuming that Conjecture 1 is true, in the Stackelberg-Stackelberg pricing game model, there exists a unique Stackelberg equilibrium under the manufacturer's price, $P_{m}^{S S T}$. By solving the first-order condition, $P_{m}^{S S T}$ is obtained.

Proof. If Conjecture 1 is true, there exists a unique global maximizer of $M P^{S S T}$. By setting $\partial \Pi_{m} / \partial P_{m}=0$, we obtain the equilibrium solution $P_{m}^{\mathrm{SST}}$. This completes the proof.

The explicit expression of $P_{m}^{\mathrm{SST}}$ is long and complicated. Instead, we present a brief version of the solving procedure in Appendix B.

\section{Numerical Examples}

This section numerically investigates the effects of parameters on the optimal equilibrium quantities. The main dataset used for the analysis is as follows: $\alpha=500, \beta_{m}=4$, $\beta_{r}=10, \quad \omega=5, \quad \delta_{1}=0.6, \quad \gamma=8, \quad \theta=0.5, \quad C_{p}=1$, $C_{r 1}=C_{r 2}=0.5$, and $C_{c}=0.2$. For this dataset, we obtain the equilibrium price and profit for each player in the developed pricing game models in the next sections.

6.1. Effect of $\omega$ on Equilibrium Quantities. Parameter $\omega$ in the recyclers' demand functions indicates the competition intensity between the two recyclers. We are interested in an investigation of the effects of the competition intensity on equilibrium prices and profits. To do this, we consider the 


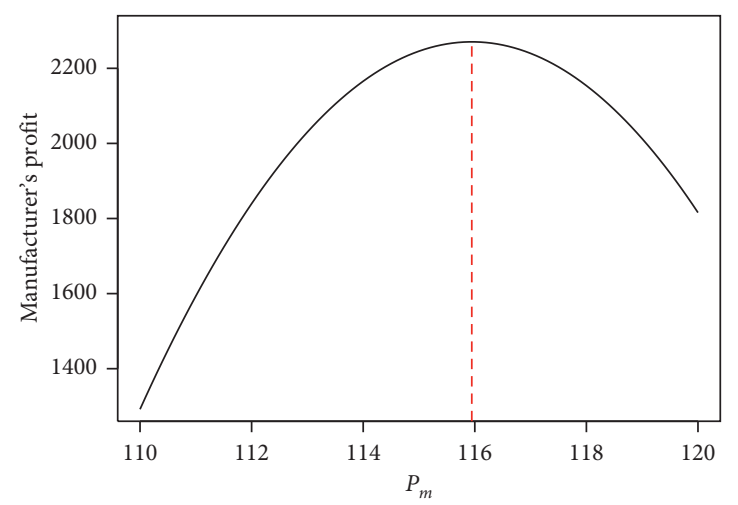

FIGURE 3: Concavity of the manufacturer's profit in the SST model.

main dataset and vary $\omega$ from 0 to 8 . The equilibrium quantities of the decision variables and the obtained profits for different values of $\omega$ are plotted in Figure 4. As the value of $\omega$ increases, we observe the following:

(i) The manufacturer's and the collector's prices increase in each of the six pricing game models.

(ii) In the NCL and the SCL models, recycler 1's price increases, while in the remaining four models, recycler 1's price decreases.

(iii) In the NCL and the SCL models, recycler 2's price increases. In the remaining four models, recycler 2's price initially increases to a certain level, i.e., it has a maximum, and then decreases.

(iv) The profit of all members except recycler 2 decreases in each of the six pricing game models.

(v) Recycler 2's profit initially increases to a certain level, i.e., it has a maximum, and then decreases in each of the six pricing game models. This is an interesting phenomenon by which a recycler with smaller market share will benefit from limited competition.

From the facts observed above, we suggest the following managerial insight:

Insight 1 . As the competition between the two recyclers intensifies, the profit of all members except recycler 2 decreases. This leads to lower total profit of the supply chain. In other words, competition has a negative effect on the profits of not only the supply chain but also its members. Note that the competition intensity $\omega$ is the key parameter for raising the prices of supply chain members when the recyclers collude with each other.

6.2. Effect of $\beta_{r}$ on Equilibrium Quantities. Parameter $\beta_{r}$ in the recyclers' demand functions indicates the manufacturer's price sensitivity with regard to the recycled materials. To investigate the effects of the manufacturer's price sensitivity on equilibrium prices and profits, we consider the main dataset and vary $\beta_{r}$ from 5.5 to 10 . Figure 5 shows the trends of the equilibrium quantities of the decision variables and the obtained profits for different values of $\beta_{r}$. As the value of $\beta_{r}$ increases, we observe the following:

(i) The manufacturer's and the collector's prices decrease in each of the six pricing game models.

(ii) In the NCL and SCL models, recycler 1's and recycler 2's prices decrease, while in the remaining four models, their prices increase.

(iii) The profits of all members in the supply chain increase in each of the six pricing game models. Therefore, the total profit of the supply chain also increases.

From the facts observed above, we suggest the following managerial insight:

Insight 2. We can infer that the demand for the finished product is an increasing function of $\beta_{r}$. This is because that, as the value of $\beta_{r}$ increases, the manufacturer's price decreases while the manufacturer's profit increases. In other words, increasing $\beta_{r}$ boosts the demands of all the members in the supply chain. These boosted demands then cause the profits of all members in the supply chain to increase. Consequently, the total profit of the supply chain also increases. Note that the manufacturer's price sensitivity $\beta_{r}$ is the key parameter for lowering the prices of supply chain members when the recyclers collude with each other.

6.3. Effect of $\delta_{1}$ on Equilibrium Quantities. Parameter $\delta_{i}$ in the recyclers' demand functions indicates the recycler $i$ 's market share. In this section, we conduct a sensitivity analysis of the market share on the equilibrium prices and profits. Varying $\delta_{1}$ from 0.5 to 0.7 , Figure 6 records the trends of the equilibrium quantities of the decision variables and the obtained profits for different values of $\delta_{1}$. As the value of $\delta_{1}$ increases (i.e., recycler 1's market share grows), we observe the following:

(i) The manufacturer's and recycler 1's prices increase in each of the six pricing game models.

(ii) The collector's and recycler 2's prices decrease in each of the six pricing game models. 

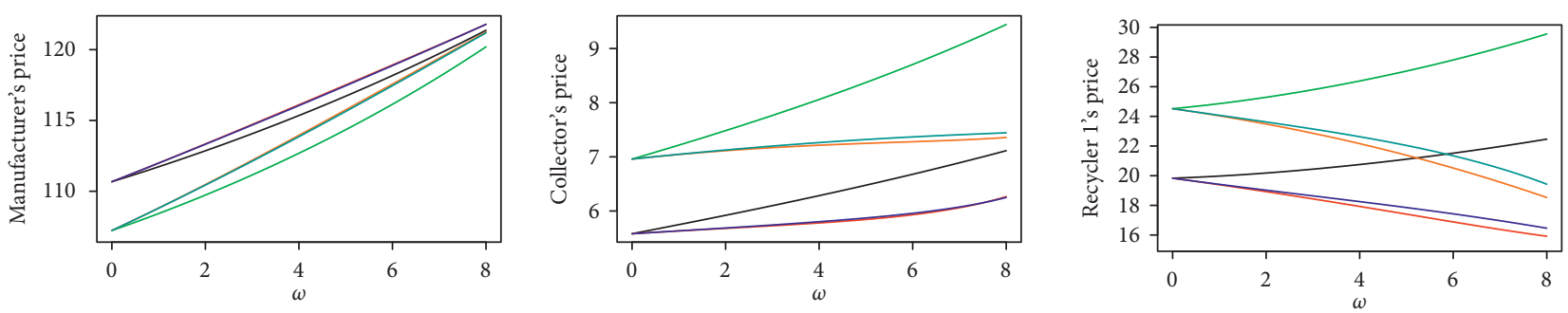

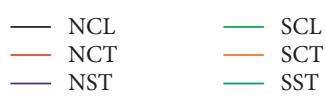

(a)
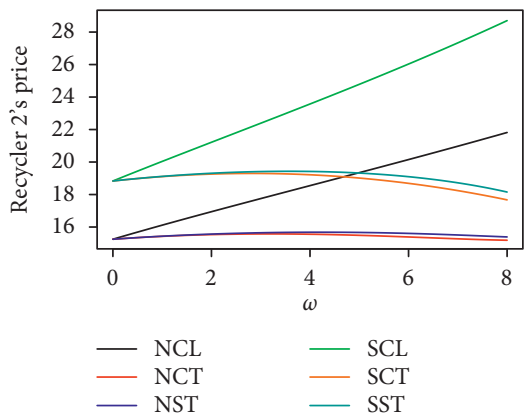

(d)

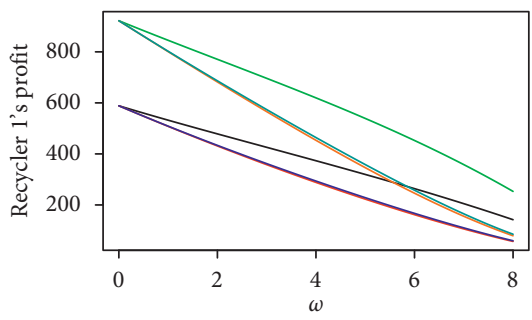

$\begin{array}{ll}- \text { NCL } & - \text { SCL } \\ \text { NCT } & \text { SCT } \\ \text { NST } & - \text { SST }\end{array}$

(g)

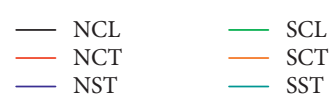

(b)
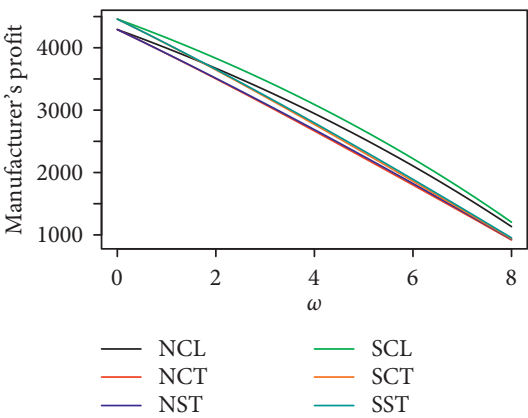

(e)
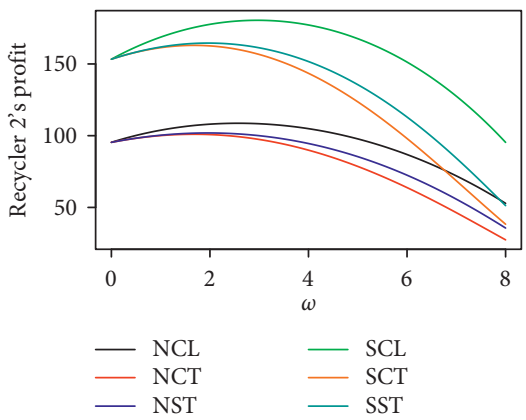

(h)

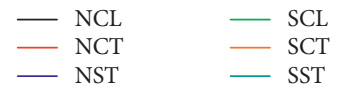

(c)

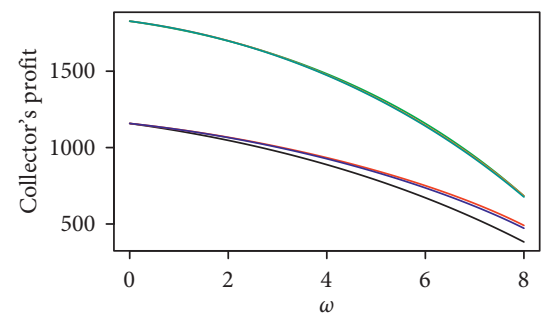

(f)
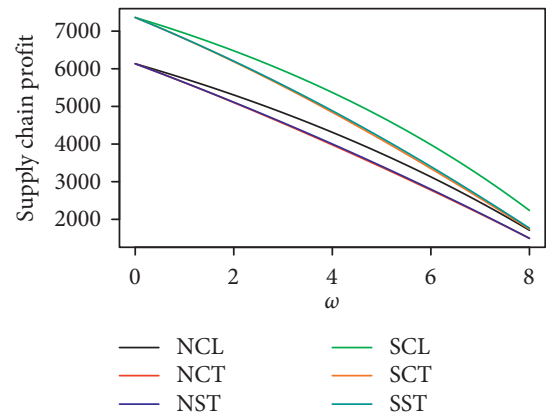

(i)

FIgURE 4: Effect of $\omega$ on equilibrium prices and profits.

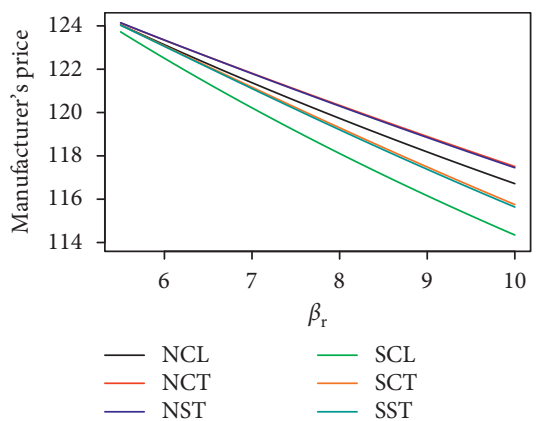

(a)
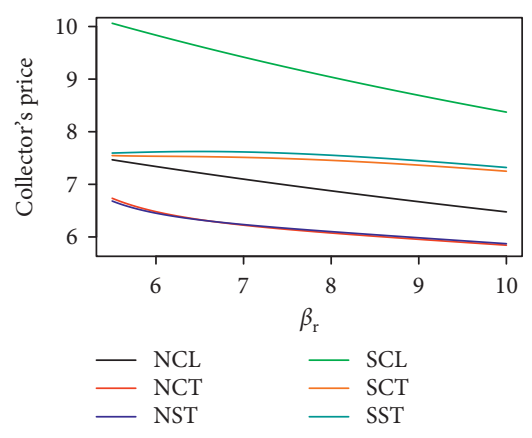

(b)
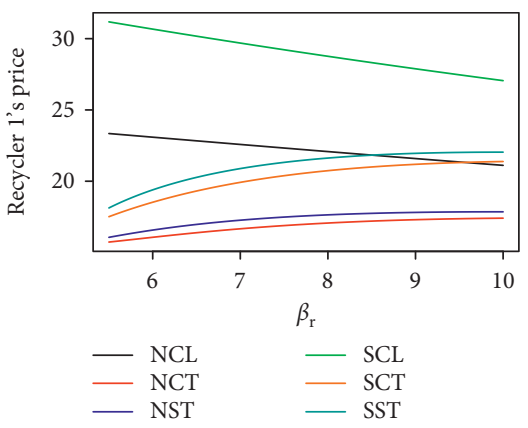

(c)

Figure 5: Continued. 


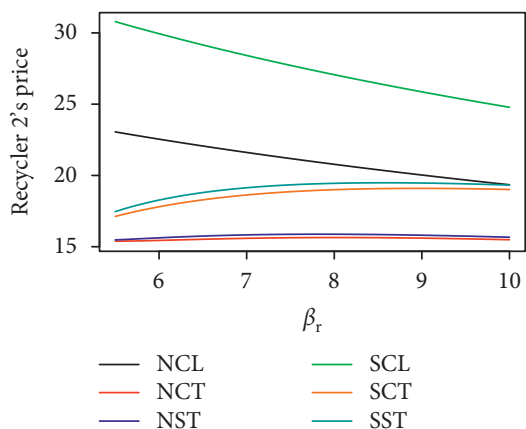

(d)
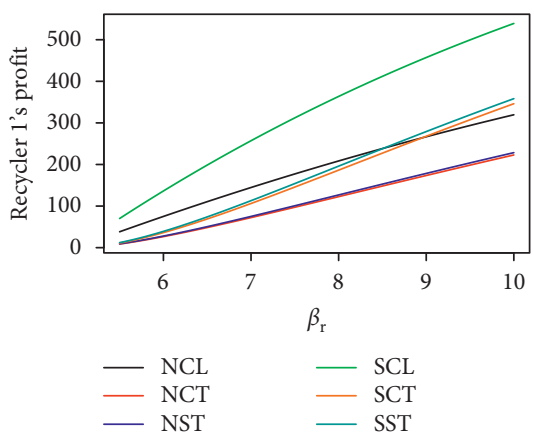

(g)

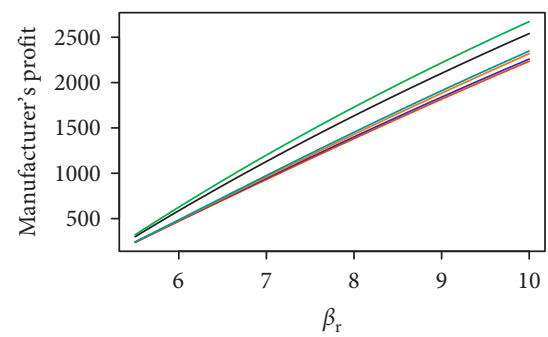

- NCL

- NST

(e)
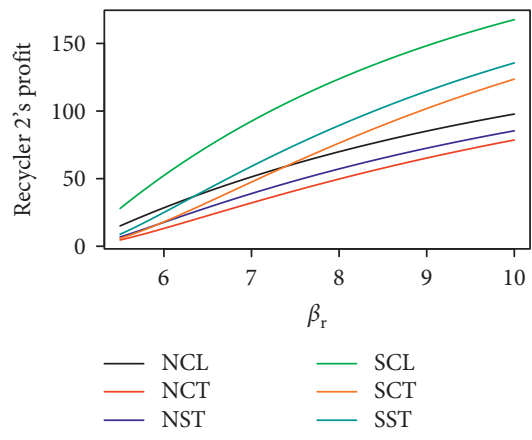

(h)

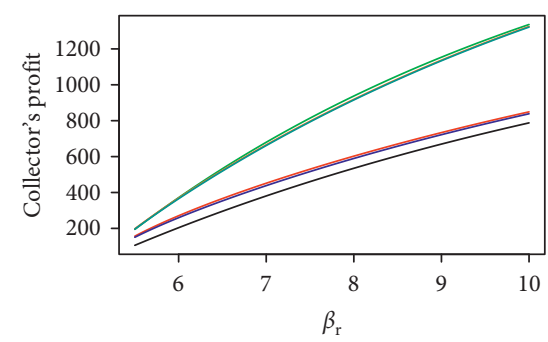

$\begin{array}{ll}\text { NCL } & - \text { SCL } \\ \text { NCT } & \text { SCT } \\ \text { NST } & \text { SST }\end{array}$

(f)

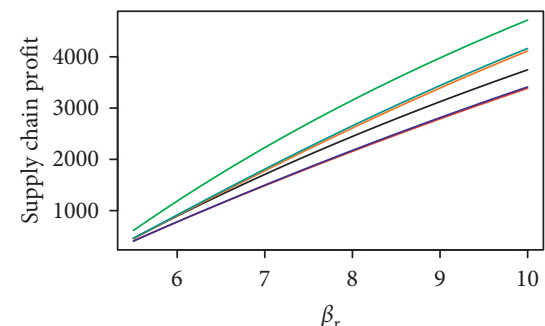

- SCL

(i)

Figure 5: Effect of $\beta_{r}$ on equilibrium prices and profits.

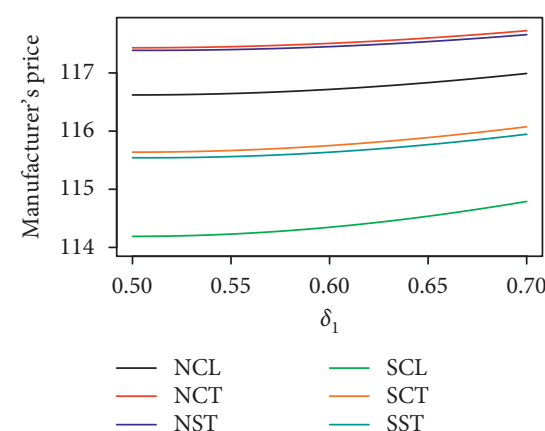

(a)

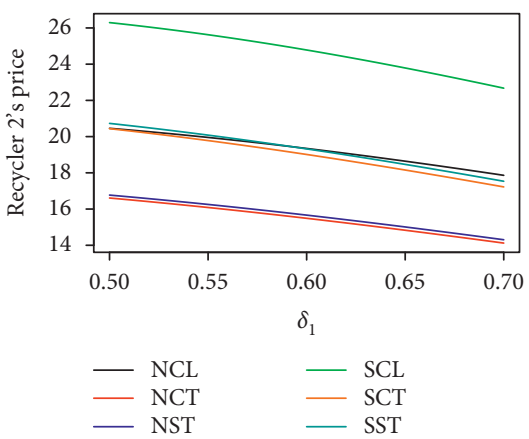

(d)

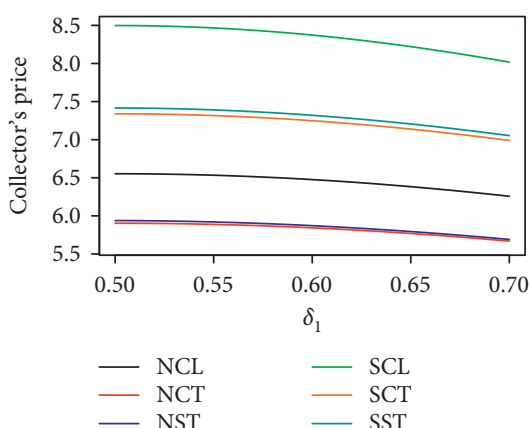

(b)

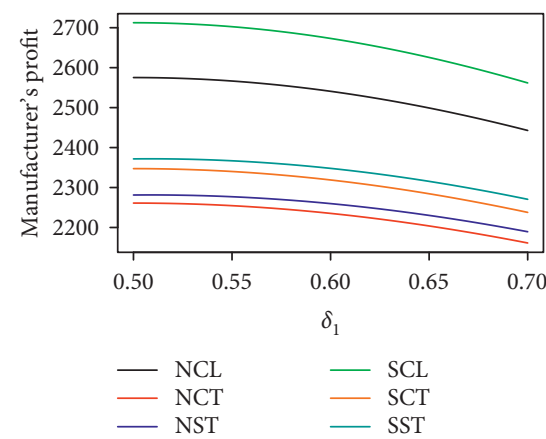

(e)

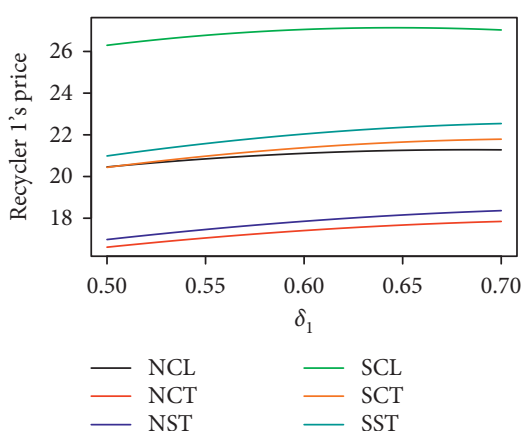

(c)

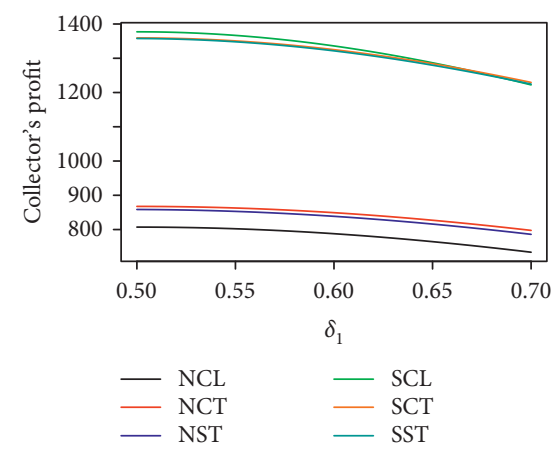

(f)

Figure 6: Continued. 


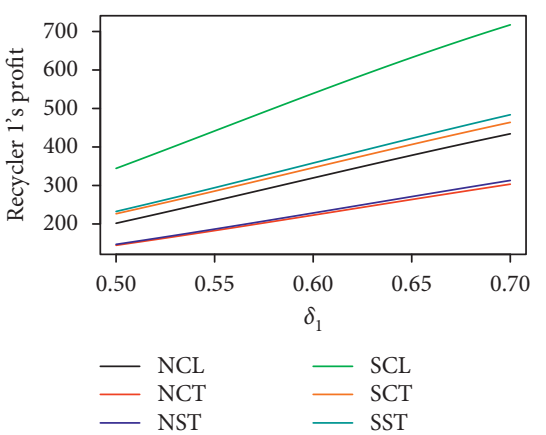

(g)

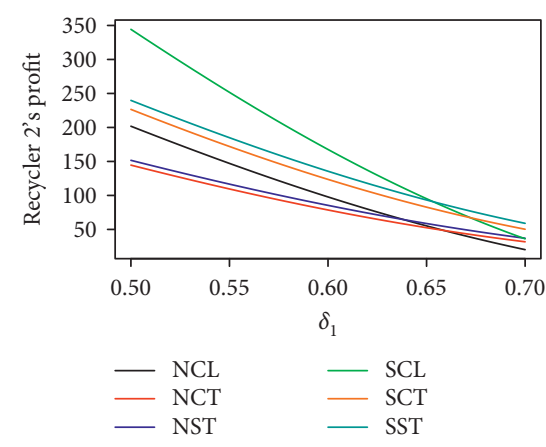

(h)

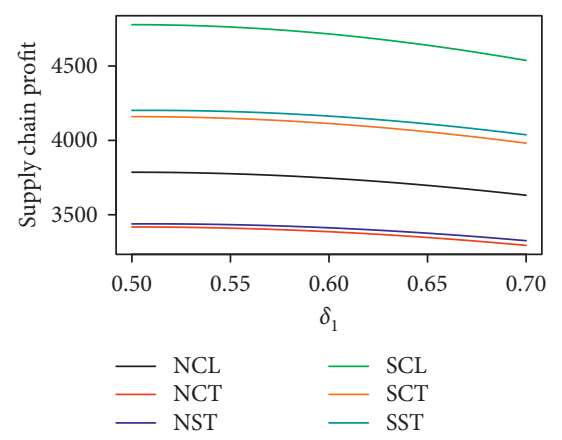

(i)

FIgURE 6: Effect of $\delta_{1}$ on equilibrium prices and profits.

(iii) The profit decreases for all members except for recycler 1 in each of the six pricing game models. Only recycler 1's profit increases.

From the facts observed above, we suggest the following managerial insight:

Insight 3. An increase in $\delta_{1}$ means that the imbalance in the market share is intensifying in the recycling market. As $\delta_{1}$ increases, only the recycler 1's profit increases, whereas the profits of the other members decrease. This causes the total profit of the supply chain to decrease. Summarizing the above, the imbalance in the market share has a negative effect on the profit of the supply chain.

6.4. Effect of $\theta$ on Equilibrium Quantities. Parameter $\theta$ in the collector's demand indicates the recyclability of the waste that can be recovered and turned into raw materials. This section investigates the effects of the recyclability degree on the equilibrium prices and profits. Varying $\theta$ from 0.1 to 0.9 , Figure 7 records the trends of the equilibrium quantities of the decision variables and the obtained profits for different values of $\theta$. As the value of $\theta$ increases, we observe the following.

In the Stackelberg game structure of the leaders group, the manufacturer's price increases. However, in the NCT and the NST models, the manufacturer's price decreases. Finally, in the NCL model, the manufacturer's price is not affected by the recyclability:

(i) The collector's price increases in each of the six pricing game models.

(ii) Recycler 1's and recycler 2's prices both decrease in each of the six pricing game models.

(iii) The profit increases for all members except for the manufacturer. Only the manufacturer's profit decreases.

From the facts observed above, we suggest the following managerial insight:

Insight 4. As $\theta$ increases, the profit increases for all members except for the manufacturer, causing the total profit of the supply chain to increase. The greater the recyclability degree of the waste is, the higher the profits for all the members involved in the recycling process become. In other words, recyclability has a positive impact on the total profit of the supply chain. Note that $\theta$ raises the price of the collector while it lowers the price of both retailers in all game models.

6.5. Effect of $\gamma$ on Equilibrium Quantities. Parameter $\gamma$ in the recyclers' demand functions indicates the quantity of the recycled materials required to produce one unit of the finished product. This section investigates the effects of the $\gamma$ on the equilibrium prices and profits. Varying $\gamma$ from 4 to 12 , Figure 8 records the trends of the equilibrium quantities of the decision variables and the obtained profits for different values of $\gamma$. As the value of $\gamma$ increases, we observe the following:

(i) The price decreases for all members except for the manufacturer in each of the six pricing game models. Only the manufacturer's price increases.

(ii) The profit decreases for all members in each of the six pricing game models.

From the facts observed above, we suggest the following managerial insight:

Insight 5. It is observed that a higher value of $\gamma$ leads to lowering the profits of all members. As $\gamma$ increases, the quantity of the recycled materials needed to meet the customer's demand increases. Moreover, the collector must collect more waste, leading to higher costs. As a result, the profit of the supply chain gradually decreases.

6.6. Effect of $\beta_{m}$ on Equilibrium Quantities. Parameter $\beta_{m}$ in the manufacturer's demand functions indicates the consumer's price sensitivity with regard to the finished product. We are interested in an investigation of the effects of $\beta_{m}$ on equilibrium of prices and profits. To do this, we consider the main dataset and vary $\beta_{m}$ from 1 to 7 . Figure 9 records the trends of the equilibrium quantities of the decision variables 


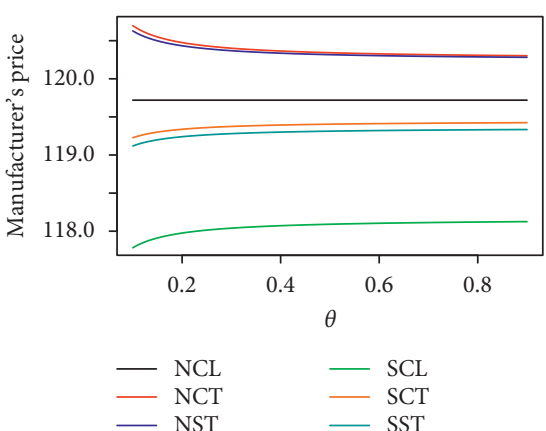

(a)

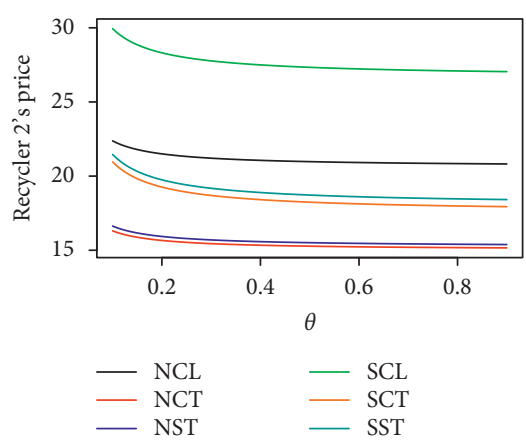

(d)
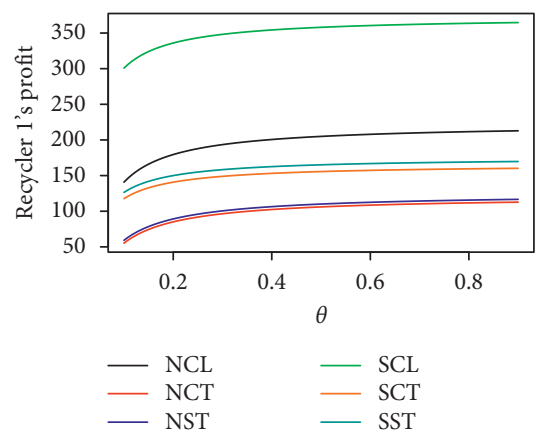

(g)
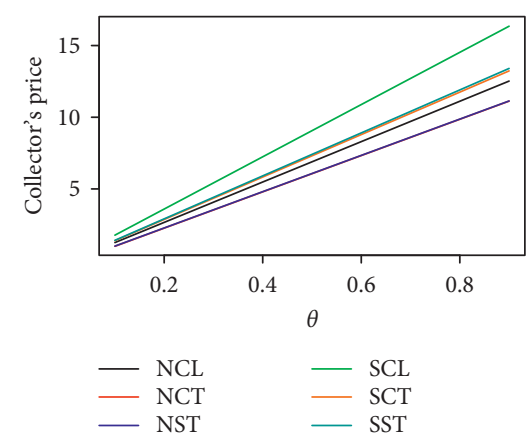

(b)
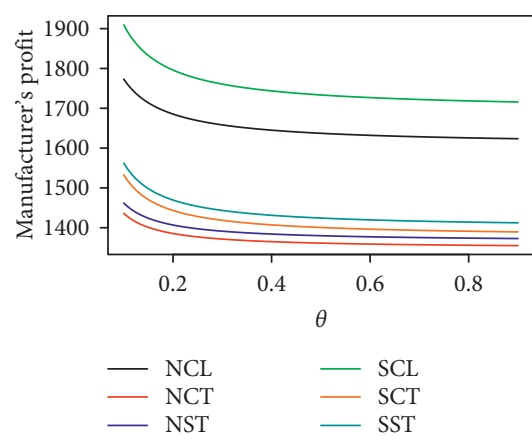

(e)
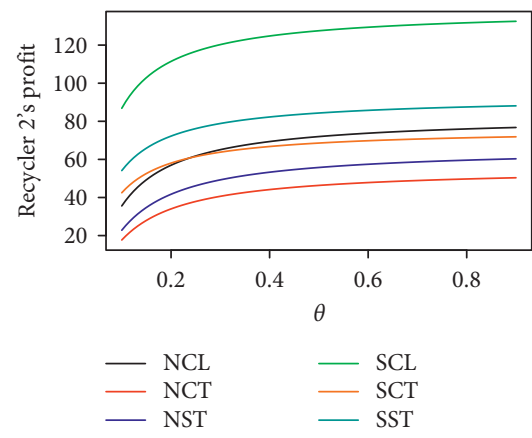

(h)
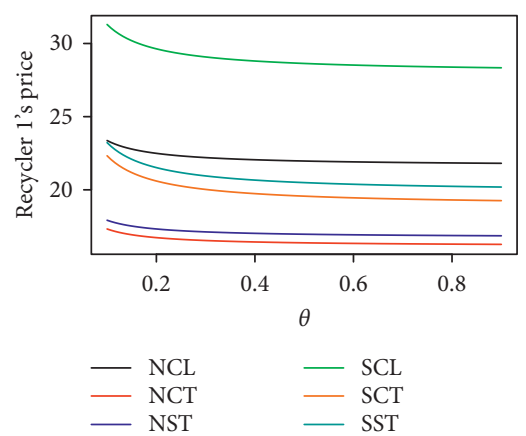

(c)
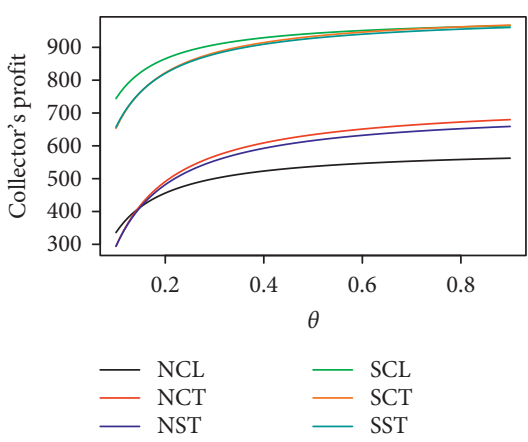

(f)

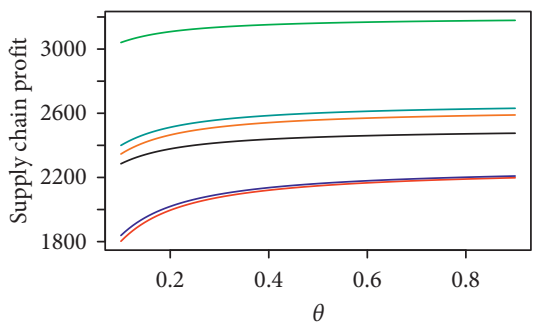

(i)

Figure 7: Effect of $\theta$ on equilibrium prices and profits.

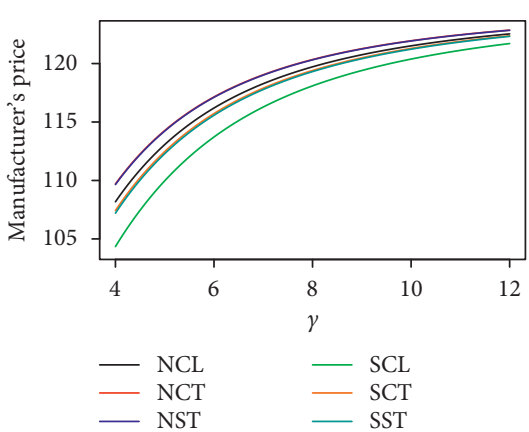

(a)

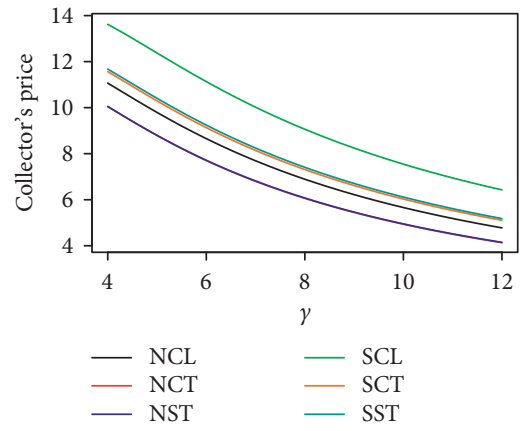

(b)

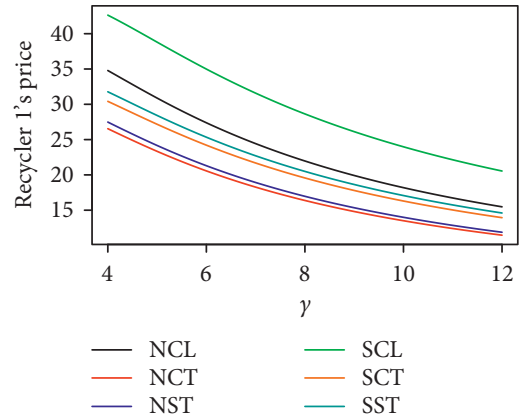

(c)

FIgUre 8: Continued. 

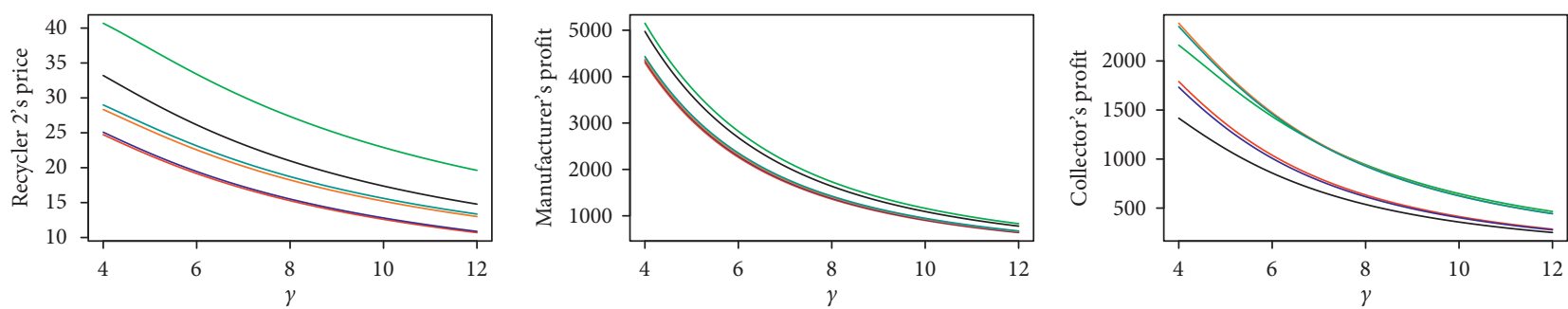

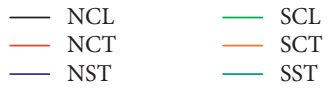

(d)

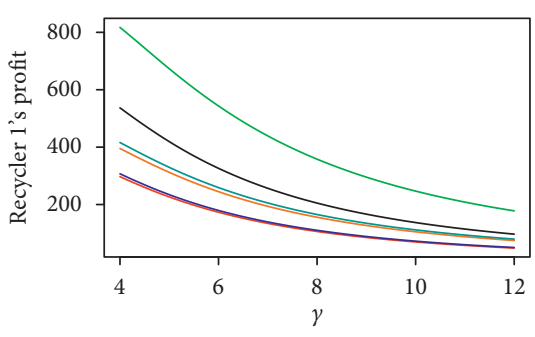

$\begin{array}{ll}\text { NCL } & - \text { SCL } \\ \text { NCT } & \text { NST } \\ \text { NCT }\end{array}$

(g)

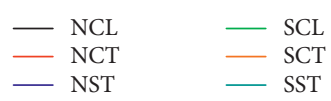

(e)

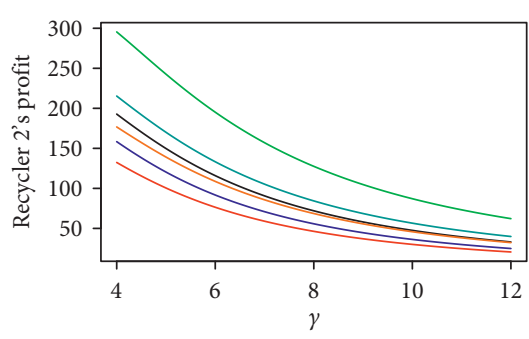

$\begin{array}{ll}\text { NCL } & \text { NCL } \\ \text { NCT } & \text { SCT } \\ \text { NST } & \text { SST }\end{array}$

(h)

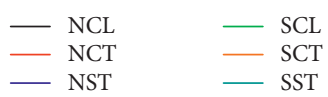

(f)

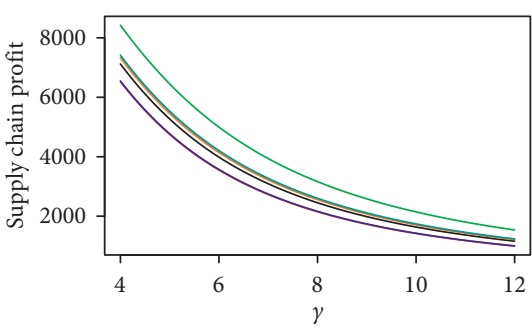

FIgURE 8: Effect of $\gamma$ on equilibrium prices and profits.
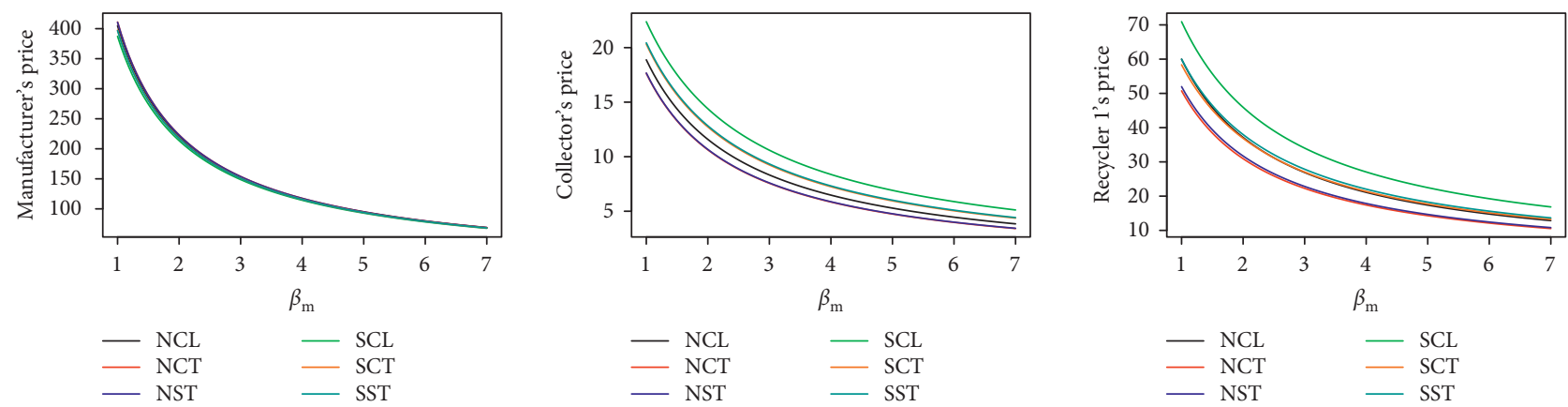

(a)

(b)

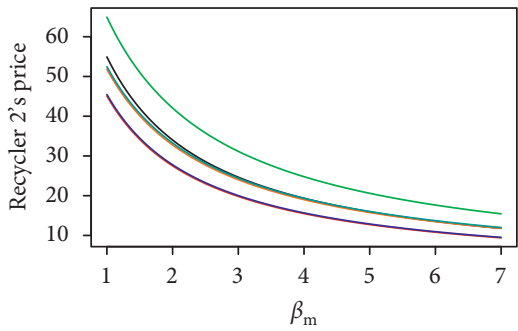

- NCL $\quad$ NCT $\quad$ SCL

(d)

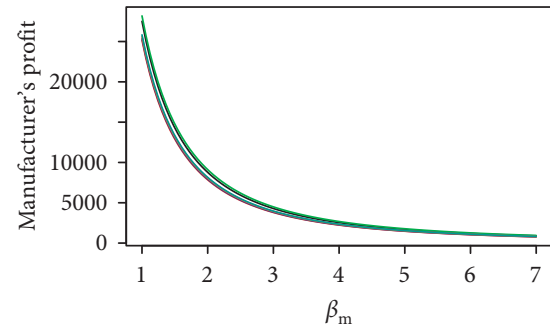

$\begin{array}{ll}\text { NCL } & \text { NCSL } \\ \text { NCT } & \text { SCT } \\ \text { NST } & \text { SST }\end{array}$

(e) (c)

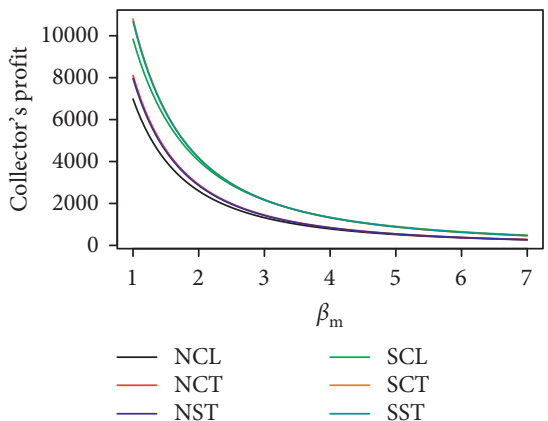

(f)

Figure 9: Continued. 


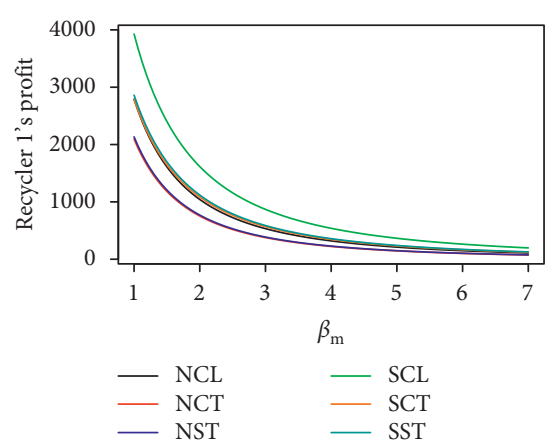

(g)

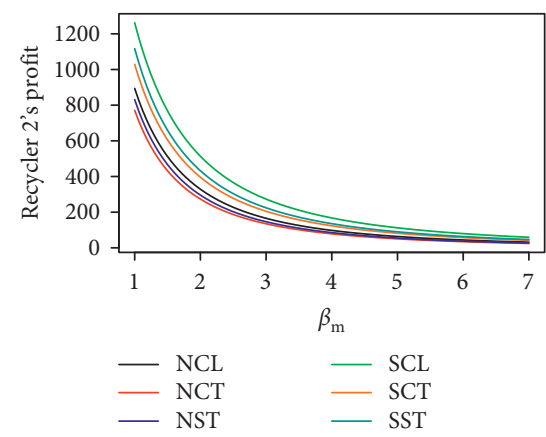

(h)

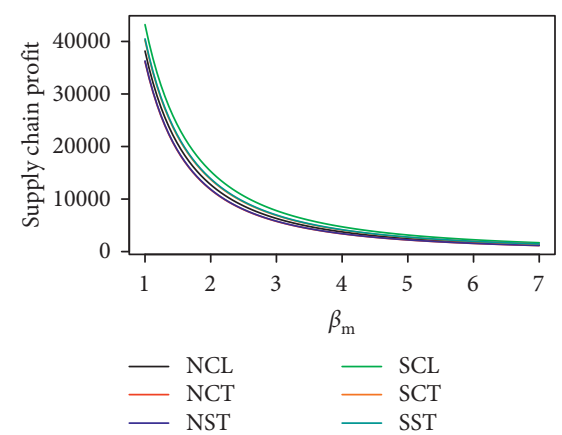

(i)

FIGURE 9: Effect of $\beta_{m}$ on equilibrium prices and profits.

and the obtained profits for different values of $\beta_{m}$. As the value of $\beta_{m}$ increases, we observe the following:

(i) Prices decrease for all members in each of the six pricing game models

(ii) Profits decrease for all members in each of the six pricing game models

From the facts observed above, we suggest the following managerial insight:

Insight 6 . It is obvious that as $\beta_{m}$ increases, the demand for the finished product decreases resulting in lowering the demands for the recyclable waste and the recycled materials, respectively. As a result, the profit for each member decreases. Note that, in all game models, $\beta_{m}$ lowers the prices of all supply chain members as well as their profits.

\subsection{Comparison among Six Pricing Game Models. From} Figures 4-9, we can find the following:

(i) In the case of the Nash game structure of the leaders group, the manufacturer's price is higher than that of the Stackelberg game structure: $P_{m}^{\mathrm{NCL}}>P_{m}^{\mathrm{SCL}}, P_{m}^{\mathrm{NCT}}>P_{m}^{\mathrm{SCT}}$, and $P_{m}^{\mathrm{NST}}>P_{m}^{\mathrm{SST}}$.

(ii) In the case of the Stackelberg game structure of the leaders group, the collector's price is higher than that of the Nash game structure: $P_{c}^{\mathrm{NCL}}<P_{c}^{\mathrm{SCL}}$, $P_{c}^{\mathrm{NCT}}<P_{c}^{\mathrm{SCT}}$, and $P_{c}^{\mathrm{NST}}<P_{c}^{\mathrm{SST}}$.

(iii) In the case of the Stackelberg game structure of the leaders group, recycler 1's price is higher than that of the Nash game structure: $P_{r 1}^{\mathrm{NCL}}<P_{r 1}^{\mathrm{SCL}}$, $P_{r 1}^{\mathrm{NCT}}<P_{r 1}^{\mathrm{SCT}}$, and $P_{r 1}^{N S T}<P_{r 1}^{S S T}$.

(iv) In the case of the Stackelberg game structure of the leaders group, recycler 2's price is higher than that of the Nash game structure: $P_{r 2}^{\mathrm{NCL}}<P_{r 2}^{\mathrm{SCL}}$, $P_{r 2}^{\mathrm{NCT}}<P_{r 2}^{\mathrm{SCT}}$, and $P_{r 2}^{N S T}<P_{r 2}^{S S T}$.

(v) In the case of the Stackelberg game structure of the leaders group, the manufacturer's profit is higher than that of the Nash game structure: $\Pi_{m}^{\mathrm{NCL}}<\Pi_{m}^{\mathrm{SCL}}$, $\Pi_{m}^{\mathrm{NCT}}<\Pi_{m}^{\mathrm{SCT}}$, and $\Pi_{m}^{\mathrm{NST}}<\Pi_{m}^{\mathrm{SST}}$. In terms of profitability, the SCL (NCT) pricing game model is the most advantageous (disadvantageous) for the manufacturer.

(vi) In the case of the Stackelberg game structure of the leaders group, the collector's profit is higher than that of the Nash game structure: $\Pi_{c}^{\mathrm{NCL}}<\Pi_{c}^{\mathrm{SCL}}$, $\Pi_{c}^{\mathrm{NCT}}<\Pi_{c}^{\mathrm{SCT}}$, and $\Pi_{c}^{\mathrm{NST}}<\Pi_{c}^{\mathrm{SST}}$. In terms of profitability, the SCL (NCL) pricing game model is the most advantageous (disadvantageous) for the collector.

(vii) In the case of the Stackelberg game structure of the leaders group, the recycler 1's profit is higher than that of the Nash game structure: $\Pi_{r 1}^{\mathrm{NCL}}<\Pi_{r 1}^{\mathrm{SCL}}$, $\Pi_{r 1}^{\mathrm{NCT}}<\Pi_{r 1}^{\mathrm{SCT}}$, and $\Pi_{r 1}^{\mathrm{NST}}<\Pi_{r 1}^{\mathrm{SST}}$. In terms of profitability, the SCL (NCT) pricing game model is the most advantageous (disadvantageous) for recycler 1 .

(viii) In the case of the Stackelberg game structure of the leaders group, the recycler 1's profit is higher than that of the Nash game structure: $\Pi_{r 2}^{N C L}<\Pi_{r 2}^{S C L}$, $\Pi_{r 2}^{\mathrm{NCT}}<\Pi_{r 2}^{\mathrm{SCT}}$, and $\Pi_{r 2}^{\mathrm{NST}}<\Pi_{r 2}^{\mathrm{SST}}$. In terms of profitability, the SCL (NCT) pricing game model is the most advantageous (disadvantageous) for recycler 2 .

(ix) In terms of the total profit of the supply chain, the Stackelberg game structure of the leaders group outperforms the Nash game structure. In addition, the recyclers' Collusion (Cournot) behavior performs the best (the worst): $\Pi_{\text {sc }}^{\mathrm{NCT}}<\Pi_{\mathrm{sc}}^{\mathrm{NST}}<\Pi_{\mathrm{sc}}^{\mathrm{NCL}}<\Pi_{\mathrm{sc}}^{\mathrm{SCT}}<\Pi_{\mathrm{sc}}^{\mathrm{SST}}<\Pi_{\mathrm{sc}}^{\mathrm{SCL}}$, where $\Pi_{s c}$ is the total profit of the supply chain.

\section{Conclusion}

In this work, we discussed a topic related to environmental sustainability through an investigation of the collecting and recycling processes of recyclable waste in a three-echelon CLSC consisting of one manufacturer, one collector, and two recyclers. This study utilized game theory to model the problem of determining the equilibrium prices of participants in the investigated supply chain considered. We assumed that the manufacturer and the collector belong to the leaders group and that the two recyclers belong to the followers group. In the leaders group, we dealt with two pricing structure types: the Stackelberg and Nash types. In 
the followers group, price competition was assumed to exist between the two recyclers, and we dealt with three types of competition behavior for the recyclers: Collusion, Cournot, and Stackelberg. With the two pricing structure types in the leaders group and the three types of competition behavior in the followers group, six different pricing game models were developed. For each of the pricing game models, the uniqueness of equilibrium and optimal pricing was analytically proved. Finally, various numerical experiments were conducted to investigate the effects of the experimental parameters on the equilibrium prices and profits of the supply chain members. To the best of our knowledge, the current paper is the first to consider the concept of selling price competition between recyclers in a three-echelon CLSC.

In terms of the total profit of this supply chain, our main findings are as follows:

(i) As the price competition intensifies between the recyclers, the total profit of the supply chain decreases

(ii) The higher the manufacturer's price sensitivity for the recycled materials is, the higher the total profit of the supply chain becomes

(iii) As the imbalance in the market share intensifies in the recycling market, the total profit of the supply chain decreases

(iv) The more likely the waste is to be recycled, the higher the total profit of the supply chain

(v) As the quantity of the recycled materials required to produce a finished product increases, the total profit of the supply chain decreases

(vi) The Stackelberg game structure of the leaders group outperforms the Nash game structure

(vii) The recyclers' Collusion (Cournot) behavior performs the best (the worst)

Several future research studies related to this topic are possible. One can modify the model to consider different coordination contracts between the players to obtain higher profits. Moreover, different demand patterns, especially of the nonlinear demand of the consumer, can be assumed when studying similar types of problems. Another possibility is to consider the price competition between manufacturers and collectors and to analyze their outcomes.

\section{Appendix}

\section{A. Solving Procedure for the Equilibrium Prices}

For all. $g \in\{\mathrm{NCT}, \mathrm{NST}\}$

Step 1: set $P_{r i}=P_{r i}^{g}, i=1,2$

Step 2: solve the equations system $\partial \Pi_{c} / \partial P_{c}=0$ and $\partial \Pi_{m} / \partial P_{m}=0$ w.r.t. $P_{c}$ and $P_{m}$, and set the roots to the collector's price, $P_{c}^{g}$, and the manufacturer's price, $P_{m}^{g}$, respectively

Step 3: calculate $P_{r i}^{g}=P_{r i}\left(P_{m}^{g}, P_{c}^{g}\right), i=1,2$.

\section{B. Solving Procedure for the Equilibrium Prices}

For all. $g \in\{$ SCT, SST $\}$

Step 1: set $P_{c}=P_{c}^{g}$ and $P_{r i}=P_{r i}^{g}, i=1,2$

Step 2: solve the equation $\partial \Pi_{m} / \partial P_{m}=0$ w.r.t. $P_{m}$, and set the root to the manufacturer's price, $P_{m}^{g}$

Step 3: calculate $P_{c}^{g}=P_{c}\left(P_{m}^{g}\right)$ and $P_{r i}^{g}=P_{r i}\left(P_{m}^{g}, P_{c}^{g}\right)$, $i=1,2$.

\section{Data Availability}

No data were used to support this study.

\section{Conflicts of Interest}

The authors declare that they have no conflicts of interest.

\section{Acknowledgments}

This work was supported by Basic Science Research through the National Research Foundation of Korea (NRF) funded by the Ministry of Education (NRF2018R1D1A3B07040887).

\section{References}

[1] F. Taghikhah, A. Voinov, and N. Shukla, "Extending the supply chain to address sustainability," Journal of Cleaner Production, vol. 229, pp. 652-666, 2019.

[2] D. O'Rourke, "The science of sustainable supply chains," Science, vol. 344, pp. 1124-1127, 2014.

[3] M.-L. Tseng, M. S. Islam, N. Karia, F. A. Fauzi, and S. Afrin, "A literature review on green supply chain management: trends and future challenges," Resources, Conservation and Recycling, vol. 141, pp. 145-162, 2019.

[4] M. Xu, Y. Cui, M. Hu et al., "Supply chain sustainability risk and assessment," Journal of Cleaner Production, vol. 225, pp. 857-867, 2019.

[5] A. A. Hervani, M. M. Helms, and J. Sarkis, "Performance measurement for green supply chain management," Benchmarking: An International Journal, vol. 12, no. 4, pp. 330-353, 2005.

[6] H. Lorentz, Y. Shi, O.-P. Hilmola, J. Srai, and K. Hung Lau, "Benchmarking green logistics performance with a composite index," Benchmarking: An International Journal, vol. 18, no. 6, pp. 873-896, 2011.

[7] A. Parmigiani, R. D. Klassen, and M. V. Russo, "Efficiency meets accountability: performance implications of supply chain configuration, control, and capabilities," Journal of Operations Management, vol. 29, no. 3, pp. 212-223, 2011.

[8] J. Sarkis, "A boundaries and flows perspective of green supply chain management," Supply Chain Management: An International Journal, vol. 17, no. 2, pp. 202-216, 2012.

[9] M. Grimmer and T. Bingham, "Company environmental performance and consumer purchase intentions," Journal of Business Research, vol. 66, no. 10, pp. 1945-1953, 2013.

[10] M. G. Luchs, R. W. Naylor, J. R. Irwin, and R. Raghunathan, "The sustainability liability: potential negative effects of ethicality on product preference," Journal of Marketing, vol. 74, no. 5, pp. 18-31, 2010. 
[11] K. Salimifard and R. Raeesi, "A green routing problem: optimising CO," International Journal of Advanced Operations Management, vol. 6, no. 1, pp. 27-57, 2014.

[12] P. C. Chen, M. C. Chiu, and H. W. Ma, "Measuring the reduction limit of repeated recycling: a case study of the paper flow system," Journal of Cleaner Production, vol. 132, pp. 98-107, 2016.

[13] J. M. Allwood, M. F. Ashby, T. G. Gutowski, and E. Worrell, "Material efficiency: a white paper," Resources, Conservation and Recycling, vol. 55, pp. 362-381, 2011.

[14] A. Ashby, M. Leat, and M. Hudson-Smith, "Making connections: a review of supply chain management and sustainability literature," Supply Chain Management: An International Journal, vol. 17, pp. 497-516, 2012.

[15] R. B. Handfield and E. L. Nichols, Supply Chain Redesign: Transforming Supply Chains into Integrated Value Systems, FT Press, Upper Saddle River, NJ, USA, 2002.

[16] M. Eskandarpour, P. Dejax, J. Miemczyk, and O. Péton, "Sustainable supply chain network design: an optimizationoriented review," Omega, vol. 54, pp. 11-32, 2015.

[17] L. Feng, K. Govindan, and C. Li, "Strategic planning: design and coordination for dual-recycling channel reverse supply chain considering consumer behavior," European Journal of Operational Research, vol. 260, no. 2, pp. 601-612, 2017.

[18] M. Huang, M. Song, L. H. Lee, and W. K. Ching, "Analysis for strategy of closed-loop supply chain with dual recycling channel," International Journal of Production Economics, vol. 144, no. 2, pp. 510-520, 2013.

[19] C. P. Baldé, V. Forti, V. Gray, R. Kuehr, and P. Stegmann, The Global E-Waste Monitor, 2017, https://www.itu.int/en/ITU-D/ Climate-Change/Documents/GEM\%202017/Global-E-waste\% 20Monitor\%202017\%20.pdf.

[20] H. Jafari, S. R. Hejazi, and M. Rasti-Barzoki, "Sustainable development by waste recycling under a three-echelon supply chain: a game-theoretic approach," Journal of Cleaner Production, vol. 142, pp. 2252-2261, 2017.

[21] A. C. S. Amaro and A. P. F. D. Barbosa-Povoa, "The effect of uncertainty on the optimal closed-loop supply chain planning under different partnerships structure," Computers \& Chemical Engineering, vol. 33, pp. 2144-2158, 2009.

[22] M. Geissdoerfer, S. N. Morioka, M. M. de Carvalho, and S. Evans, "Business models and supply chains for the circular economy," Journal of Cleaner Production, vol. 190, pp. 712721, 2018.

[23] N. M. Bocken, I. de Pauw, C. Bakker, and B. van der Grinten, "Product design and business model strategies for a circular economy," Journal of Industrial and Production Engineering, vol. 33, pp. 308-320, 2016.

[24] R. C. Savaskan, S. Bhattacharya, and L. N. Van Wassenhove, "Closed-loop supply chain models with product remanufacturing," Management Science, vol. 50, pp. 239-252, 2004.

[25] R. C. Savaskan and L. N. Van Wassenhove, "Reverse channel design: the case of competing retailers," Management Science, vol. 52, pp. 1-14, 2006.

[26] Y. J. Chen and J.-B. Sheu, "Environmental-regulation pricing strategies for green supply chain management," Transportation Research Part E: Logistics and Transportation Review, vol. 45, no. 5, pp. 667-677, 2009.

[27] A. Atasu, L. B. Toktay, and L. N. Van Wassenhove, "How collection cost structure drives a manufacturer's reverse channel choice," Production and Operations Management, vol. 22, no. 4, pp. 1089-1102, 2013.

[28] X. Hong, Z. Wang, and D. Wang, "Decision models of closedloop supply chain with remanufacturing under hybrid dual- channel collection," The International Journal of Advanced Manufacturing Technology, vol. 68, no. 5-8, pp. 1851-1865, 2013.

[29] N. Wang, Q. He, and B. Jiang, "Hybrid closed-loop supply chains with competition in recycling and product markets," International Journal of Production Economics, vol. 217, pp. 246-258. In press, 2019.

[30] N. M. Modak, N. Modak, S. Panda, and S. S. Sana, "Analyzing structure of two-echelon closed-loop supply chain for pricing, quality and recycling management," Journal of Cleaner Production, vol. 171, pp. 512-528, 2018.

[31] N. M. Modak, S. Panda, and S. S. Sana, "Two-echelon supply chain coordination among manufacturer and duopolies retailers with recycling facility," The International Journal of Advanced Manufacturing Technology, vol. 87, no. 5-8, pp. 1531-1546, 2015.

[32] S. Saha, S. P. Sarmah, and I. Moon, "Dual channel closed-loop supply chain coordination with a reward-driven remanufacturing policy," International Journal of Production Research, vol. 54, no. 5, pp. 1503-1517, 2016.

[33] L. Liu, Z. Wang, L. Xu, X. Hong, and K. Govindan, "Collection effort and reverse channel choices in a closed-loop supply chain," Journal of Cleaner Production, vol. 144, pp. 492-500, 2017.

[34] B. C. Giri and S. K. Dey, "Game theoretic analysis of a closedloop supply chain with backup supplier under dual channel recycling," Computers \& Industrial Engineering, vol. 129, pp. 179-191, 2019.

[35] J. Wei, Y. Wang, J. Zhao, and E. D. R. Santibanez Gonzalez, "Analyzing the performance of a two-period remanufacturing supply chain with dual collecting channels," Computers \& Industrial Engineering, vol. 135, pp. 1188-1202, 2019.

[36] H. Jian, M. Xu, and L. Zhou, "Collaborative collection effort strategies based on "Internet + recycling" business model," Journal of Cleaner Production, vol. 241, p. 118120, 2019.

[37] I. E. Nielsen, S. Majumder, and S. Saha, "Game-theoretic analysis to examine how government subsidy policies affect a closed-loop supply chain decision," Applied Sciences, vol. 10, no. 1, p. 145, 2020.

[38] S. Saha, I. E. Nielsen, and S. Majumder, "Dilemma in two game structures for a closed-loop supply chain under the influence of government incentives," Journal of Industrial Engineering International, vol. 15, no. S1, pp. 291-308, 2019.

[39] N. M. Modak, S. Panda, and S. X. Sana, "Pricing policy and coordination for a two-layer supply chain of duopolistic retailers and socially responsible manufacturer," International Journal of Logistics Research and Applications, vol. 19, pp. 487-508, 2016.

[40] S. Panda, N. M. Modak, and L. E. Cárdenas-Barrón, "Coordinating a socially responsible closed-loop supply chain with product recycling," International Journal of Production Economics, vol. 188, pp. 11-21, 2017.

[41] N. M. Modak, S. Sinha, S. Panda, and N. Kazemi, “Analyzing a socially responsible closed-loop distribution channel with recycling facility," SN Applied Sciences, vol. 1, no. 10, p. 1189, 2019.

[42] N. M. Modak and P. Kelle, "Using social work donation as a tool of corporate social responsibility in a closed-loop supply chain considering carbon emissions tax and demand uncertainty," Journal of the Operational Research Society, 2019, In press.

[43] N. M. Modak, N. Kazemi, and L. E. Cárdenas-Barrón, "Investigating structure of a two-echelon closed-loop supply chain using social work donation as a Corporate Social 
Responsibility practice," International Journal of Production Economics, vol. 207, pp. 19-33, 2019.

[44] N. Kazemi, N. M. Modak, and K. Govindan, "A review of reverse logistics and closed loop supply chain management studies published in IJPR: a bibliometric and content analysis," International Journal of Production Research, vol. 57, no. 15-16, pp. 4937-4960, 2019.

[45] 8 Companies that Only Sell 100 Percent Recycled Products, https://greenbusinessbureau.com/blog/8-companies-that-onlysell-100-percent-recycled-products.

[46] M.-B. Jamali and M. Rasti-Barzoki, "A game theoretic approach to investigate the effects of third-party logistics in a sustainable supply chain by reducing delivery time and carbon emissions," Journal of Cleaner Production, vol. 235, pp. 636652, 2019.

[47] W. Li and J. Chen, "Backward integration strategy in a retailer Stackelberg supply chain,” Omega, vol. 75, pp. 118-130, 2018.

[48] N. M. Modak, S. Panda, and S. S. Sana, "Three-echelon supply chain coordination considering duopolistic retailers with perfect quality products," International Journal of Production Economics, vol. 182, pp. 564-578, 2016.

[49] T. Chakraborty, S. S. Chauhan, and N. Vidyarthi, "Coordination and competition in a common retailer channel: wholesale price versus revenue-sharing mechanisms," International Journal of Production Economics, vol. 166, pp. 103$118,2015$.

[50] S. M. Seyedhosseini, S. M. Hosseini-Motlagh, M. Johari, and M. Jazinaninejad, "Social price-sensitivity of demand for competitive supply chain coordination," Computers \& Industrial Engineering, vol. 135, pp. 1103-1126, 2019. 